\title{
Der Text ohne Bedeutung oder die Erstarrung der Angst Zu Stifters letzter Erzählung Der fromme Spruch
}

\author{
Von Albrecht Koschorke und Andreas Ammer (München)
}

\begin{abstract}
Stifters letzte Erzählung arbeitet an der Auslöschung aller Formen von Differenz. Es entsteht ein Text, in dem die restriktiv eingesetzten und verwalteten Zeichen zu völliger Bedeutungslosigkeit neigen. Die Tautologie ist Mittel eines Schweigetrainings, das aus der Angst des Autors vor seinem eigenen Material, vor der Revolte der Sprache hervorgeht.

Stifter's last story works on the extinction of difference. The signs in the text are dealt with in a highly restrictive manner, tending to posture a total absence of significance. The author's fear of his own material, of the revolt of language, leads him to employ tautology as a vehicle for the cultivation of silence.
\end{abstract}

I.

In Stifters letzter Erzählung wird viel geredet. ${ }^{1}$ Vieles, was in dem Text, der Macht und Würde eines sprachlichen Zeichens im Titel trägt, gesagt wird, wird doppelt gesagt. Der fromme Spruch bedient sich der Regeln der Rede nicht, um Informationen austauschbar zu machen. Getauscht wird nur was jeder weiß. Der Austausch von Wörtern richtet keine Differenzen auf oder behebt sie und erstattet den gesichtslosen Figuren, von deren Physiognomie nur ihre Ununterscheidbarkeit der Rede wert ist, keine Individualität zurück. Ihre Sprache ist nur

${ }^{1}$ Stifter hat in der Uberarbeitung der ersten Reinschrift diese Tendenz weiter verstärkt; vgl. Kurt G. Fischers Nachwort zur sog. "ersten Fassung" in Adalbert Stifter, Der fromme Spruch (1962), S. 115-45, S. 125. Zur Kritik dieser ungenügenden Erstausgabe der Urfassung vgl. Ruthilde Frischenschlager, "Uber Editionsschwierigkeiten des 'Frommen Spruches,"” VASILO, 19 (1970), 11-22. Ebd. findet sich auch eine exakte Auflistung von Bettina Frey, "Die Änderungen Stifters im Manuskript B der Erzählung 'Der fromme Spruch,"” S. 23-86. Neben solch textkritischen Tabellen bilden bezeichnenderweise die Nachworte der Stifter-Ausgaben die einzigen Einzeluntersuchungen zum Text: Neben Gustav Wilhelms Bemerkungen zur ersten, von den tiefgreifenden Änderungen Johannes Aprents bereinigten Ausgabe (A.S., Sämtliche Werke, Bd. XIII/1, 1958 [!], S. LXXXIII-XCVIII) fanden wir nur noch Konrad Steffens Nachwort zu A.S., Gesammelte Werke in 14 Bdn. [1964], V, 525-32. Kursorische Bemerkungen anderweits sind im folgenden kursorisch erwähnt. Vernachlässigt werden konnten die wenigen Erwähnungen des Frommen Spruches, die vor 1958 erschienen und sich auf die von Aprent entstellte Fassung beziehen. 
eine lautliche Verdoppelung des bereits Gesagten. Stets wissen die miteinander Redenden das Nämliche und werden nicht müde, eben dies noch auszusprechen: "Ich hätte von dem nämlichen Gegenstande gesprochen, wenn ich den Anfang zu manchen gehabt hätte" (679). ${ }^{2}$ Nach dem Muster solcher Zelebration des Einverständnisses haben die Gespräche Neigung, sich selbst thematisch in die zeremoniellen Bestandteile zu zerlegen, aus denen sie fast ausschließlich bestehen. Die Rede reduziert sich auf einen performatorischen Kommentar ihrer selbst. Immerfort ist während des Sprechens das Sprechen thematisch, werden dessen Regeln einsichtig gehalten, bleibt das Verfahren der Rede auf sich hin transparent. Sprache befindet sich stets auf der Schwelle, sich ihres Charakters als Sprachspiel und Äquivalenztausch bewußt zu werden. Denn wenig nur wird gesagt, wenn gesagt wird: "es muß doch einmal von dem geredet werden, wovon geredet werden muß" (718) und also der Vollzug der Worte deren Inhalt eliminiert hat. Als vorausgesetzte und doch ohne Unterlaß betriebene Operation der Sprache erscheint der Ausschluß dessen, was Sprache zum Leben bringt: des Unbekannten, Ungesagten, Fremden. Die Rede bedient sich der Mittel der Insignifikanz, die ihren eigenen Begriff annullieren. Wenn ein solches Verfahren der Affirmation des Schweigens durch Sprechen nicht auf gefährliche und verräterische Paradoxien auflaufen soll, muß es den Hermetismus der scheinbar unscheinbaren Form der Tautologie für sich in Anspruch nehmen. ${ }^{3}$ Freilich ist das, was Stifters Spätstil zum Ärgernis der Literaturwissenschaft hat werden lassen, aus unserer Sicht gerade Dokument seiner Kraft. Die Tautologie gefährdet und steckt noch den mit ihrer Stummheit an, der sich interpretatorisch über sie erheben will; sie hat etwas von einer subversiven Macht durch die Gegenwehr, die sie der Sinnfabrikation des Interpreten leistet. Man darf vermuten, daß Stifter solche Verfahrensweisen nicht nur schildernd in seine Kunstwerke ver-

\footnotetext{
${ }^{2}$ Soweit möglich zitieren wir nach der gut erreichbaren Winkler-Ausgabe: Sämtliche Werke in fünf Einzelbänden: Nach dem Text der Erstdrucke oder der Ausgabe letzter Hand (o. J.) Unsere Siglen bezeichnen: BS - Bd. 1 Bunte Steine und Erzäblungen / MSB Bd. 2 Die Mappe meines Urgroßvaters, Schilderungen, Briefe / STU - Bd. 4 Studien. Seitenangaben ohne Sigle beziehen sich ausschließlich auf den Frommen Spruch in BS, 663-736.

${ }^{3}$ Den Begriff der Tautologie gegenüber Stifter in Anschlag gebracht zu haben, ist das Verdienst von Friedrich Aspetsberger, "Stifters Tautologien," VASILO, 15 (1966), 23-44. Von "realistisch-tautologischen Sinnimputaten" im Alterswerk spricht Hans Joachim Piechotta, Ordnung als mythologisches Zitat: Adalbert Stifter und der Mythos in Karl Heinz Bohrer (Hrsg.), Mythos und Moderme (1983), S. 83-110, S. 86. Bemerkenswert sind in diesem Zusammenhang auch die Ergebnisse von Piechottas ausgedehnter Studie Aleatorische Ordnung: Untersuchungen zu extremen literarischen Positionen in den Erzäblungen und dem Roman "Witiko" von Adalbert Stifter (1981). - Zur subversiven Kraft der Tautologie vgl. Roland Barthes, Racine ist Racine, in ders., Mythen des Alltags (1964), 27-29: "Die Tautologie ist immer aggressiv" (S. 27).
} 
bannt, sondern auf eine für den Künstler, den manischen Sprachindustriellen, ${ }^{4}$ ruinöse Weise an ihnen Anteil nimmt; daß er sie nicht nur als Technik, sondern als Erfahrung statuiert. Wenn das stimmt, dann sind - was freilich erst das Ende unserer Analyse erweisen kann - die spielerischen Sprachzeremonien der Figuren im Frommen Spruch Phantasmagorien der Angst des Produzenten vor seinem eigenen Material: den Wörtern; einer Angst allerdings, die das Stadium von Drohung und Fluchtversuch übersprungen oder hinter sich gelassen und das der Starre erreicht hat.

An einer einzigen Stelle, die resümierend am Ende der eigentlichen Handlung steht, geben die Figuren der Erzählung hellsichtigen Aufschluß über die Methode des Textes, dessen Spielbälle sie sind, und dessen Vorgehen sie zu ihrem eigenen gemacht haben. Es ist nicht die Sprachnot der späteren Sprachkritiker, die hier zum Verstummen führt, vielmehr eine Furcht vor Ausdruck und jeglicher Bedeutung, die den Exzeß der Gedanken bloßlegen würde:

"Meine liebe Schwester Gerlint," sagte der Oheim, "nun ist die größte Sorgfalt anzuwenden, daß niemand erfahre, welche Gedanken wir gehabt haben."

"Ich werde sie niemanden offenbaren," sagte die Tante.

"Ich auch nicht," antwortete der Oheim, "wenn nur nicht jemand durch Ahnungen, Deutungen und dergleichen darauf kommt."

"Das wagt niemand zu denken," sagte die Tante. (730)

Dem folgt der ganze Text. Dem folgen seine Figuren auf eine doppelte Art. Machen sie sich doch auf, "durch Andeutungen, Deutungen und dergleichen" die von ihnen selbst erst konstituierte, reduzierte Welt zu entziffern. Insofern stehen sie mit dem Leser auf einer Stufe, sind (scheiternde) Interpreten ihrer eigenen Zeichenwelt, Analytiker, Detektive und Hermeneutiker wie wir, die wir die Interpreten der Interpreten zu spielen haben. Dabei wendet sich die Manie des Deutens, wie alle Manien, gegen den Deutenden selbst. Das Beobachten des freien Spiels der Signifikanten produziert - so Stifters Veto - nur Irrtümer, syntaktisches Stottern und Unsagbarkeiten. So beschreibt jedenfalls ein weiterer Selbstkommentar der Protagonisten die gedankliche Abweichung, die aus der Fehlinterpretation von Zeichen folgt:

Der Oheim schwieg.

Die Tante sprach: "Das wäre ja, wenn es wäre, das ist, ich weiß es nicht, sage es mir, das wäre merkwürdig."

$\ldots$

4 Solche technoiden Metaphern können sich durchaus auf den Landschaftsdichter Stifter berufen, der bei der Arbeit am Witiko behauptet, er habe die "Bände in der Fabrik." Zit. n. der immer noch anregenden Biographie von Alois R. Hein, Adalbert Stifter: Sein Leben und seine Werke (1952, zuerst 1904) 2 Bde., S. 738. 
"Das ist," sagte der Oheim, "es kommt zuweilen einmal vor, aber hier zweimal, es wäre, wie du sagst, merkwürdig." (719)

Der Text, der allenthalben von Verdoppelungen lebt, multipliziert auch unseren Leseakt, indem er die Decodierung seiner Zeichen zum eigenen Thema macht. Sein eigenes poetologisches Verfahren der Duplikation, auf der die hier ausgesprochene Verwirrung beruht, läßt er durch seine Protagonisten mit dem zweifachen Kommentar "merkwürdig” versehen. Hier pure Selbstironie zu vermuten, hieße den Schutzmantel der erzählerischen Operation mit dem verwechseln, was er verbergen soll. Deuten, besagt die Geschichte, ist fehlgehen, ${ }^{5}$ und sie funktioniert nur, weil sie es zu guter Letzt unnötig macht. Sie will keinen Interpretationsraum lassen und so der ästhetischen Tendenz nach wohl auch nicht gelesen werden. Unter den Visionen vom Ende der Kunst, an denen das neunzehnte Jahrhundert reich ist, ist dies die verschwiegenste.

II.

Niemand wird einem, der zu weit gegangen ist, vorwerfen können, er verfehle sein Ziel. Der alte Stifter hat diesen Vorwurf erfahren. ${ }^{6}$ Er sah sich von der zeitgenössischen Kritik fast stets auf die Studien, bestenfalls den Nachsommer zurückverwiesen. Sein Spätstil aber ist die Konsequenz des Gesamtwerks. Er treibt die Kräfte zu abschließender radikaler Gestaltung, die seine literarische Produktion von der Buchform der Studien an bestimmten und von der For-

${ }^{5}$ Nur im Titel berührt diesen Gedanken Margret Walter-Schneider, "Das Unrecht des Wählens: Bemerkungen zu Adalbert Stifters spätem Stil,” Wirkendes Wort, 32 (1982), 267-75.

${ }^{6}$ Noch Fritz Martini spricht von einem "Ziselieren, das die formale Erlesenheit, das ästhetische Kunstvergnügen Selbstzweck werden läßt" und "etwas Problematisch-Esoterisches" gewinnt (Deutsche Literatur im bürgerlichen Realismus 1848-1898, 3. Aufl. [1974], S. 552).

In diesem Sinne zitiert auch Wilhelm 1958 (Anm. 1), der Stifter im Frommen Spruch an der "Grenze seiner Kunst" angelangt glaubt, Hermann Bahr, der das "Künstlerische bis zur Künstelei gesteigert" fand. Gegenüber Hein bedeutet dies bereits eine Aufwertung der Erzählung. Nach dem letzteren ist sie "das förmlichste, abgeschmackteste und langweiligste, was je in einem Unterhaltungsbuche zum Ausdruck gelangte," während Hermann Uhde sie in einer Rezension von 1874 schlechterdings als "unerträglich langweilig" apostrophierte (alles S. XCVIIf.; das Hein-Zitat konnte von uns nicht verifiziert werden).

Die auf zwei professorale Gutachten gestützte Ablehnung der Erzählung durch Leo Tepe, den Herausgeber der Aachener Katholischen Welt, ist nachzulesen bei Fischer 1962 (Anm. 1), S. $99 \mathrm{ff}$. Tepe stuft den Frommen Spruch als "zu langweilig," "fast lächerlich" ein und fügt hinzu: "ich will Ihren literarischen Ruhm nicht verdunkeln helfen." Avancierte Kunst sieht sich immer wieder den gleichen Widerlegungsstrategien gegenüber. 
schung unter Begriffen wie Abklärung, Elimination von Konflikten, Ausfall psychologischer Darstellung, Zurücktreten des Subjektiven, Drang zu sprachlicher Klassizität immer wieder namhaft gemacht worden sind.? Die Energie und Strenge, mit denen der alte Stifter dem eingeschlagenen Weg bis zum Ende folgt, widerlegen die über lange Zeit gestellte Diagnose eines Nachlassens der dichterischen Kräfte. Wenn von einem Mißlingen der letzten Arbeiten gesprochen werden darf, so muß es in der Konsequenz der ästhetischen Probleme selbst liegen, denen gegenüber sein Stil sich vom Kanonischen zum Apokryphen fortbildet. Wer auf biographischem Niveau argumentiert, wird einen plausiblen Grund dafür liefern müssen, daß Stifter, stets in der Nähe eines finanziellen Ruins, nicht anders zu können scheint, als sich an unlesbaren Erzählungen abzuarbeiten; daß er, während er sich im Besitz von historischen Stoffen zu einem monumentalen Romanzyklus glaubt, ${ }^{8}$ monatelang an den letzten Kapiteln des kaum rezipierten Witiko feilt; daß er zum vierten Mal die Mappe aufgreift, um die ihre erzählerische Anlage prägende Aporie eines nichtsubjektiven Redens vom Ich noch weiter zu verschärfen. Die beharrliche Sabotage der Lesergewohnheiten, die Entfernung vom Publikum, das unbeirrte Hervorbringen langweiliger Texte können nicht einfach mit Erschlaffung des poetischen Vermögens begründet werden. Zudem wäre der Punkt des Umschwungs nicht lokalisierbar. Bei aller Unterschiedenheit der Werke im einzelnen läßt sich die Kontinuität nicht verkennen, die von der Höhe des Nachsommer zur Absonderlichkeit der allerletzten Erzählung reicht, die zu Stifters Lebzeiten keinen Abnehmer fand und

\footnotetext{
7 So summarisch wie die Untersuchungen zum Altersstil Stifters den Frommen Spruch behandeln, seien sie hier angeführt: Ingeborg Maschek, Stifters Alterserzäblungen: Eine Stiluntersuchung, Phil. Diss. (1962). - Michael Böhler, "Die Individualität in Stifters Spätwerk: Ein ästhetisches Problem,” DVjs, 43 (1969), 652-689. - Walter Weiss, "Stifters Reduktionen," in Eugen Thurnherr (Hrsg.), Germanistische Studien (1969), S. 199-220. Rosemarie Hunter, "Stifters Späterzählungen - Familiengeschichten?" in W.C. Kraft (Hrsg.), Proceedings Pacific Northwest Conference on Foreign Languages, Bd. XXIV, Corvallis, S. 155-158. - Eva Arts, Studien zur Erzäblkunst Adalbert Stifters: Der Aufbau der vier späten Erzählungen (1976). - H. Seidler, "Adalbert Stifters späte Erzählkunst im Rahmen des bürgerlichen Realismus,” in Stifter-Symposion '78 (1979). - Walter-Schneider 1982 (Anm. 5). Besser ist die Lage in bezug auf die anderen Späterzählungen. Stellvertretend seien zwei Arbeiten von Friedrich Aspetsberger genannt: "Die Aufschreibung des Lebens: Zu Stifters 'Mappe," VASILO, 27 (1978), 11-38. - "Stifters Erzählung 'Nachkommenschaften," Sprachkunst, 6 (1975), 238-260. Hier finden sich 238ff. auch einleitende Bemerkungen zum Frommen Spruch.

${ }^{8}$ Stifter bringt das immer wieder in seinen Briefen an Heckenast zur Sprache. "Wenigstens Pläne häufen sich bei mir, daß ich auch in meinem 100sten Jahre nicht damit fertig wäre" (Brief vom 7.3.1860). Zitate, die nicht der Winkler-Ausgabe entnommen werden konnten, werden zitiert nach der Prag-Reichenberger-Ausgabe, 1904-1960 (im folgenden abgekürzt als SW), Briefe jedoch nur durch das Datum nachgewiesen.
} 
erst zwei Jahre später von Aprent in entstellter Form veröffentlicht wurde.9 Der alte Stifter hat keine neuen Stoffe erfunden. Er überschreibt gleichsam die Themen, die ihn sein Leben lang beschäftigten, mit neuer reinlicher Schrift. Die Nachkommenschaften suchen unter seinem Ringen mit der Malerei einen Schlußstrich zu ziehen. Witiko soll durch strenge Historik die phantastischen Ubertretungen des Hochwald ungeschehen machen. ${ }^{10}$ Gegen alle biographische Erfahrung schreibt Stifter im Waldbrunnen den Juliana-Stoff, der schon der Erzählung Katzensilber zugrundeliegt, zu einem glücklichen Ende um. Es scheint, als ob er in den letzten Jahren seines Lebens alles Offene, alle Ungelöstheiten, alle stehengebliebenen Diskrepanzen hätte immanent ästhetisch begleichen wollen. Gegen die sonst herrschende Dramaturgie des Scheiterns sucht er, mit welcher Gewaltsamkeit auch immer, eine Logik gelingender Texte aufzurichten. In enger Verwandtschaft mit dem Kuß von Sentze, der an den Scharnast-Komplex anschließt, schreibt Der fromme Spruch in einer Vielzahl von thematischen und motivischen Aspekten die Nachsommerwelt fort. Auch diese Fortschreibung unterliegt den für Stifter charakteristischen Produktionsgesetzen. Sie verringert den Radius aller im Nachsommer noch wirksamen Impulse, angefangen vom Bildungsgedanken und der Naturerschließung bis hin zu den Bedeutungsfeldern der Symbole und zur sprachlichen Präsenz der Personen, und läßt sie auf den Rang von Spurenelementen herabsinken. Aber gerade die fortgesetzte Verengerung des Schweigegürtels, der um Schauplatz und Personen gelegt ist, zeigt auch die Parallelität im Zustandekommen beider Texte auf. Wie das antiquarische Denken, das den Nachsommer prägt, ${ }^{11}$ entstehungsgeschichtlich auf die gescheiterte Revolution von 1848 reagiert, so dürften der archaisierende Legendenton und die schon nicht mehr beschaulich zu nennende Enge des Lebenshorizontes im Frommen Spruch von dem Ereignis des Krieges 1866 befördert worden sein. Briefliche Äußerungen Stifters ${ }^{12}$ zeigen, wie er nur mehr mit einem neuerlichen Paroxysmus von Schweigen und Hypochondrie auf ein welthistorisches Faktum reagieren kann, das seinem in der Restaurationsperiode programmatisch gehärteten Zutrauen in die Gesetzmäßigkeit der Welt einen vollends desperaten Charakter verleiht und den Außendruck auf seine Dichtung

9 Vgl. Christian Winkler, "Die Änderungen Johann Aprents in Stifters 'Frommem Spruch,"” VASILO, 19 (1970), 87-117. Aprent bereinigt den Text auf eine Weise von allem Verstörenden, daß seine Änderungen im vermeintlich besser verkäuflichen Stil der Zeit beinahe als Indiz für bedeutsame und provokative Elemente des Textes herhalten können. Uber die Prinzipien der Textredaktion unterrichtet Aprents Briefwechsel mit Heckenast, mitgeteilt von Moritz Enzinger, "Zur Jubiläumsausgabe von Stifters 'Frommem Spruch," in ders., Gesammelte Aufsätze zu Adalbert Stifter (1967), S. 23-33.

${ }^{10} \mathrm{Vgl}$. Hein (Anm. 4), II, 700.

${ }^{11}$ Vgl. Hannelore und Heinz Schlaffer, Studien zum ästhetischen Historismus (1975), S.112-139.

12 "Es ist Pflicht gegen mich, daß ich Allem, was mich zu lebhaft an die Thatsache erinnert, zu entfliehen suche." (An Amalia Stifter, 24.-27.7.1866). 
verstärkt, indem es deren innere Ordnung einem weiteren Schub von Wirklichkeitsentzug unterwirft. Die Adelssphäre im Frommen Spruch hat einen Grad von Irrealität, Selbstbezüglichkeit und Formalisierung erreicht, der daran denken läßt, sie für eine Karikatur der patriarchalischen Bildungswelt des Freiherrn Risach zu halten. ${ }^{13}$ Es läge nahe, dahinter eine ironische Wendung Stifters zu vermuten. Der fromme Spruch wäre dann wie auch Der Kuß von Sentze eine Adelssatire, allerdings als Satire selbst schon von offen anachronistischer Art und zudem mit dem Mangel behaftet, auktoriale Distanz an keiner Stelle eindeutig im Text verankert zu haben. Stifters eigener Kommentar stützt diese Lesart, dem ersten Augenschein entgegen, kaum. Auf einen von zwei Gutachten untermauerten Ablehnungsbescheid des Herausgebers der Katholischen Welt, Leo Tepe, erwidert er:

Da sind zwei Fälle möglich. Entweder ist der Geist, der in meiner Arbeit weht, nicht gefaßt worden. Dann erscheinen alle Beziehungen, die ihn vermitteln sollen, als nichts bedeutend und völlig leer, also geradehin langweilig. Es sollte allerdings die Lächerlichkeit nicht des hohen Adels, dessen Benehmen bei uns durchgängig leicht und fein ist, sondern gewisser Leute auf dem Lande mit veralteten Formen nicht gerade satirisch sondern scherzend dargestellt werden. Diese Leute sollten aber doch gut und ehrenwert sein.... Es ist... möglich, daß die Beziehungen bei einem etwas schnelleren Lesen nicht gefaßt werden. Dann ist natürlich alles zunichte. Solches ist bei Meisterwerken vorgekommen. Mozarts Don Juan fiel in Wien durch. Goethes Iphigenie hatte in der zweiten Fassung nicht einmal Herders Beifall.

Die zweite Möglichkeit ist, daß meine Arbeit wertlos ist. Jedenfalls macht mich $\mathrm{Ihr}$ Urteil und das Urteil der Männer, die Sie mir genannt haben, sehr mißtrauisch gegen meine Arbeit. Nur macht es mich auch stutzig, daß das Urteil so ganz verwerfend lautet, was eher auf ein Mißverstehen hinweist. Sollte denn der Mann, der mit solcher Liebe arbeitet, und von dem andere Arbeiten doch so manchem lieb geworden sind, plötzlich etwas ganz Nichtiges hervorbringen?...

Ich werde Ihrem Wunsche gemäß eine andere Erzählung machen, und suchen, wie in den Studien für ein größeres Publikum genießbar zu sein. ${ }^{14}$

Der halbe Versuch dieses Rechtfertigungsschreibens, den erhobenen Vorwurf der Lächerlichkeit vom Text auf das dargestellte Milieu abzuleiten, tritt hinter der Parteinahme des Dichters gerade für den formalen Charakter seiner Erzählung zurück. Es reicht nicht aus, zur Begründung einer sprachlichen Tonlage, die zwischen Komik und Lächerlichkeit nicht unterscheiden läßt, das obskure Sujet anzuführen, auf das sich der Autor darstellerisch verpflichtet habe. Vielmehr scheint die Milieuwahl ihrerseits bedingt durch ein Interesse am Aufschreiben von Ordnung, das unter Vorgabe realistischer Erzählweise gezwungen ist, angemessene Fiktionen heranzuziehen, und sie nur noch im Bereich eines - betonter-

${ }^{13}$ Vgl. Rudolf Wildbolz, Adalbert Stifter: Langeweile und Faszination (1976), $136 \mathrm{f}$.

$14 \mathrm{BS}, 749 \mathrm{f}$. (Brief vom 31.10.1867). 
maßen, denn der erste Satz nennt die Jahreszahl $1860^{15}$ - anachronistischen Zeremoniells findet. Die oft diagnostizierte Komik der Erzählung ist weniger eine dem Fundus der Erzählhaltungen in auktorialer Souveränität entnommene humorige Stimmungslage als Konsequenz der immanenten Bewegung von Stifters Dichtung überhaupt: Folge des ins Unzeitgemäße treibenden Zwangs, die Dichtung auf Harmonie zu verpflichten, dessen Produkt das weltenthoben Wunderliche des Spätstils und die Verkarstung seiner Sprache ist. Uberhaupt besteht eine eigentümliche Unangemessenheit zwischen dem Text und allen Versuchen, ihn mit den Mitteln philologisch geschärfter Inhaltsangabe oder einfühlender Ergründung der Autorintention zu begreifen. Der Text durchkreuzt eine Lesererwartung, die an den herkömmlichen Kategorien fiktionalen Erzählens geschult ist. Das haben die wenigen zeitgenössischen Leser auf ihre Weise sehr genau registriert. Die Vorwürfe, die er auf sich gezogen hat: Abstraktheit der Handlung, leere Redundanz der Sprache, Belanglosigkeit der Fabel, Aushöhlung einer an die Gesetze der Plausibilität gebundenen Fiktion -, deuten auf seine Verabschiedung der damals gültigen Erzählregeln hin. Andererseits haben die naive Erzählhaltung, der altertümliche Habitus und die Suggestion einer trivialen Lesbarkeit des Textes verhindert, daß dieser von den Gewohnheiten eines progressiven Literaturbegriffs aus rezipierbar gewesen wäre. Mit seiner letzten Erzählung betritt Stifter ein Niemandsland zwischen zwei historischen Rezeptionsweisen. Sie markiert eine Stelle - ähnlich vielleicht wie in der Musikgeschichte die von Schönberg angerufene späte Kammermusik von Brahms -, an der ein durchgehaltener Klassizismus schließlich in eine Grenzbegehung des Gebiets der traditionellen Sprachlichkeit hinüberführt. Stifters Wunderlichkeit ist Modernität ohne das Vokabular der Moderne.

III.

$$
\begin{aligned}
& \text { Eduard und Kunigunde } \\
& \text { Kunigunde Eduard. } \\
& \text { Eduard und Kunigunde } \\
& \text { Kunigunde Eduard. }{ }^{16}
\end{aligned}
$$

Die Handlung im Frommen Spruch lautet folgendermaßen. Die Geschwister Gerlint und Dietwin von der Weiden wünschen aus Familienerwägungen die

\footnotetext{
15 Aprent hat sie gestrichen, um die "unmögliche Geschichte" wenigstens historistisch zu entschärfen. Bezeichnenderweise wußte er um die Unmöglichkeit seines Unterfangens: "Die Personen leben in unserer Zeit, in allem ist der Hauch der Gegenwart ... und alles Weglassen der Jahreszahl, der Namen der Rosen, des schwarzen Frackes u. dgl. hilft nichts" (Enzinger 1967 [Anm. 9], S. 26). Obwohl sie es nicht wahrhaben will, erkennt sich die Epoche in ihrem erstarrten Bild.

${ }^{16}$ Motto: "Eduard und Kunigunde," in Musenklänge aus Deutschlands Leierkasten, Repr. o.J., zuerst vor 1849 .
} 
Heirat der ihnen ähnlichen Adoptivkinder: ihrer Nichte Gerlint und des Neffen Dietwin. Sie ziehen die beiden zu diesem Zweck in ihre Nähe. Doch die erhoffte Neigung der jungen Leute zueinander scheint sich auch nach Ablauf einiger Jahre nicht zu ergeben. Nach dem Verständnis der Alten häufen sich im Gegenteil die Indizien, daß kreuzweise die Nichte dem Oheim, der Neffe der Tante zugetan ist. ${ }^{77} \mathrm{Um}$ einer Fehlentwicklung entgegenzusteuern, beschließen Oheim und Tante eine Reise. Dieser Beschluß führt endlich zur wechselseitigen Erklärung der Jungen, die Alten sehen ihren Irrtum ein, und nach einer angemessenen Frist wird Hochzeit gefeiert.

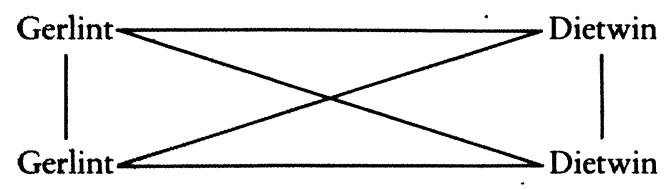

Unter den trivialen Sujets, die Stifter nicht wenigen seiner Erzählungen unterlegte, ${ }^{18}$ scheint dieses Handlungsschema das trivialste zu sein. Vom Stoff her eignet es sich für eine Verwechslungskomödie oder für ein zwischen Zerrissenheit und Doppeltheit der Personen aufgespanntes Psychodrama. Von beiden Möglichkeiten macht Stifter praktisch keinen Gebrauch. Er zeigt sich weder an effektvollen Verwicklungen noch an der Ausbreitung psychischer Ambivalenzkonflikte oder Identitätskrisen noch sonst an Formen seelischer Desorganisation interessiert. Er behandelt den Stoff als eine wenig originelle Variation des bürgerlichen Themas, Gefühls- und Vernunftgründe, Vorbestimmtheit und persönliche Neigung zu harmonisieren. Mit diesem Generalnenner der Herstellung richtiger Verhältnisse stimmt eine Traditionsspur zusammen, die auf Stücke wie Kotzebues Einakter Der Mann von vierzig Jahren (1795), wesentlicher aber auf

17 Während das erste dem Goethe-geschulten und patriarchalischen Jahrhundert noch einging, war Aprent gegenüber der zweiten Verwirrung der Gefühle völlig ratlos und eliminierte sie aus dem Text: "Kann denn diese sonst so schön gezeichnete Frau das glauben?” (An Heckenast, 16.7.1868) - “Aber daß ein junger Mann aus Neigung nach der Verbindung mit einer alten Frau strebe, ist widernatürlich" (an Heckenast, 12.8.1868; vgl. Enzinger 1967 [Anm. 9], S. 27 u. 29). Widernatürlich wäre die Verbindung laut Aprent, weil Neffe und Tante keine Kinder mehr zeugen könnten. Aprent 'wagt nicht zu denken,' daß Unfruchtbarkeit das Phantasma des Textes sein könnte.

18 Vgl. Gundel Mattenklott, Sprache der Sentimentalität (1973), S. 53. Stifters Sujets erfuhren natürlich bereits zeitgenössische Kritik. Nicht die berüchtigt-bekannte Hebbels sei hier erwähnt, sondern die eines Nachrufes aus der Wiener Morgenpost vom 29.1.1868. Nach einer zwölfzeiligen Zusammenfassung der Handlung von Granit, die mit den Worten beginnt: "Der Dichter betrachtet einen Stein," heißt es abschließend: "Man sieht, so kurz und einfach hätte sich 'Granit' erzählen lassen. O diese Weitschweifigkeit Stifters!" (zit. n. Hein 1952 [Anm. 4], S. 975). S. a. Moritz Enzinger, Adalbert Stifter im Urteil seiner Zeit (1968). 
Goethes Vertiefung des Stoffes in der Novelle "Der Mann von funfzig Jahren" aus den Wanderjabren zurückverweist. ${ }^{19}$ Auf den bezüglich Ambiente, Symbolverwendung und Personenkonstellation wichtigsten Entsprechungstext, Goethes Wablverwandtschaften, wird noch einzugehen sein..$^{20}$ Eine unmittelbare Anregung zum Frommen Spruch könnte neben solchen kulturellen Leitbildern die Erzählung Gerhardine aus dem unter dem Pseudonym Ernst Ritter erschienenen Novellenband Mohnkörner gewesen sein, den Stifter 1846 rezensierte. ${ }^{21}$ Stifters Text ist dabei eine Art von negativer Intertextualität wesentlich. Wenn er sich auf die sei es katastrophische (Wablverwandtschaften), melodramatische (Mobnkörner) oder komödiantische (Kotzebue) Bearbeitung seines Stoffes durch Vorgänger bezieht, dann allein unter der Form der Aussparung, der Begradigung oder des Stillschweigens. Er läßt weder den thematischen Komplex von Alterseitelkeit und notwendiger Entsagung zur Hauptsache werden, noch gibt er allgemein den vorgeprägten Tendenzen zur Psychologisierung oder zur

19 Nicht umsonst beginnt der Fromme Spruch mit dem fünfzigsten Geburtstag eines Mannes. Marianne Thalmann, Johann Wolfgang von Goethe, 'Der Mann von fünfzig Jabren' (1948), behandelt S. 28-41 und S. 47-50 auch Stifters Erzählung.

${ }^{20}$ Jürgen Kolbe, Goethes 'Wablverwandtschaften' und der Roman des 19. Jabrhunderts (1968), behandelt dieses Thema nicht, weil es "einer eigenen Untersuchung wert wäre." "Zudem scheint in 'Der Nachsommer' und in der Erzählung 'Der fromme Spruch' eher eine indirekte Gegenwendung zu Goethes Roman vorzuliegen” (S. 132). Helga Bleckwenn, Stifter und Goethe (1977), widmet den Wablverwandtschaften einige Seiten, erwähnt aber den Frommen Spruch nicht. G. Wilhelm (Anm. 1) sieht nur Parallelen zur Novelle der Wunderlichen Nachbarskinder (S. LXXXVf.).

Ab 1866, der Entstehungszeit des Frommen Spruches, häufen sich in Stifters Briefen wieder Notizen wie "Ich las dann etwas Göthe" (an Amalia, 30.10.1866) und Vergleiche zwischen dem "große[n] Göthe" und dem kleine[n] Stifter" (an Heckenast, 27.10.1866). Die Wahlverwandtschaften wie der Fromme Spruch wurden höchstwahrscheinlich in der Karlsbader Kur konzipiert: "Ich tröste mich mit Göthe, der auch Karlsbad öfter besuchen mußte. Aber ihm wird es leichter gewesen sein." (An Heckenast, 3.12.1866) - Die Parallelen zwischen den Werken sind bis in Einzelheiten hinein - sowohl Ottilie wie Gerlint lernen etwa in der Erziehungsanstalt Kleider "selber entwerfen" (689) - deutlich erkennbar.

${ }^{21}$ Vgl. SW (Anm. 8), XVI, 340-46. - Den Hinweis verdanken wir Ulrich Dittmann. In der Gerhardine der unter Pseudonym veröffentlichenden Frau von Binzer heiratet ein Mann die Mutter statt der ihn liebenden Tochter; letztere vermählt sich daraufhin mit einem väterlichen Freund, so daß zu guter Letzt alle Beteiligten unglücklich werden. Gegenüber solchen belanglosen Rührseligkeiten bewahrt Stifter sein Niveau gerade durch Trockenlegung der sentimentalen Ingredienzien seiner Stoffe. Zu Stifters überaus günstiger Rezension mag übrigens das Vorwort der Verfasserin beigetragen haben. In ihren Novellen, schreibt sie, "geschieht durchaus nichts Außerordentliches, ja ... eigentlich gar nichts!" Das Buch "ist, wie schon sein Titel andeutet, bestimmt, den Leser sanft in einen ruhigen Schlummer zu lullen! Hält es ihn wider Erwarten wach, fesselt es vielleicht sogar seine Aufmerksamkeit, so müssen wir uns mit dem leidigen Spruch entschuldigen, daß man nicht immer kann wie man will!" 
Analyse sozialer Verhältnisse nach.2 Er unternimmt keinerlei Anstalten, die geometrische Anlage des Textes, seinen schematischen Aufbau, die vorgegebene Personensymmetrie zu verbergen oder durch Elemente von Lebensnähe und Anschaulichkeit zu stützen. ${ }^{23}$ Eine Erzählweise, die derart ihre Formalität herausstreicht, verdient es, unter formalen Gesichtspunkten untersucht zu werden.

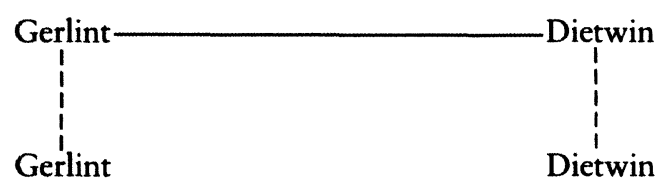

Die immanente Ausführung des Personenschemas, die der Text vollzieht, durchläuft in der Art fortschreitender Enthüllung die drei Stadien der Geschwisterliebe, der Verkreuzung der Neigungen und endlich der Liebe der jungen Leute, die zur Ehe bestimmt sind. Wie die Jungen als Verdoppelungen der Alten in die Handlung eintreten - sie tragen die gleichen Namen und ähneln ihnen trotz des Altersunterschiedes bis zur Ununterscheidbarkeit -, so stellt von der Handlungsstruktur her auch die Eheschließung der jungen Leute einen Stellvertretungsakt dar. In dem personalen Viereck, das der Text aufspreizt, wirken alle Kräfte zentripetal in Richtung auf Aufhebung der Abstände zwischen den Personen, sei es durch Neigung oder durch Ähnlichkeit. Das findet seinen deutlichsten Ausdruck in der bisher von keiner Einzelinterpretation berücksichtigten Tatsache, daß unausgesprochen im Zentrum der Geschichte das Inzestverlangen der Geschwister steht. Von diesem Inzestverlangen leiten sich überhaupt das symbolische Spiel des Textes und damit die wenn auch minimale Dynamik der Ereignisse her. Wird es zwar nicht namhaft gemacht, so gibt es doch Formen der Andeutung, Auslassung und argumentativen Unvollständigkeit, durch die es jenseits der Schweigeränder des Textes spürbar ist. Den stärksten Beweis für sein Vorhandensein liefern die Geschwister in ihrem eröffnenden Gespräch. Eine breit ausgeführte Exposition schildert beider Zusammenkunft zur Feier des gemeinsamen Geburtstages. Von dem Gespräch, das sie im Rahmen ihres alljährlichen Familienrats führen, nimmt die gesamte Handlung ihren Ausgang. Sie beschließen die Zusammenführung von Neffe und Nichte. Zwar gehe jugendliche Neigung ihre eigenen Wege und "Ehen werden in dem Himmel geschlossen," so stimmen sie in zeremoniellem Wechselgespräch überein, über-

${ }^{22}$ Fischers Betonung des "sozialkritische[n] Element[s]" (Anm. 1; S. 123) läßt sich von akzidentiellen Ingredienzien (u. a. der Weber-Frau) verführen.

${ }^{23}$ In diesem Punkt geht die professorale Kritik von Lindemann und Ebeling, die Tepe zur Ablehnung des Frommen Spruches heranzieht, in ihrem Unverständnis nicht allzuweit am Text vorbei, wenn sie behauptet: "Die Erzählung ist unnatürlich; solche steife Personen gibt es nicht,... der Stil ist gezwungen und voll von Widerholungen" (Tepe an Stifter, 17.10.1867). Natürlich gibt es solche Personen nicht. Sie sind Literatur pur: bis aufs Skelett reduziert. 
deutlich seien aber die Hinweise auf eine Bestimmung der beiden füreinander. "Es ist wunderbar" sagt der Oheim,

daß wir zwei, du und ich, an dem nämlichen Monatstage geboren worden sind, nur du um sechs Jahre später. Und heißen wir nicht Dietwin und Gerlint? Und ist es nicht wunderbar, $\mathrm{da} ß$ die zwei jüngeren Dietwin und Gerlint, wenn sie auch nicht an dem nämlichen Monatstage geboren worden sind, doch gerade auch wieder um sechs Jahre voneinander abstehen?... Viel wunderbarer aber ist es noch, daß in den Zügen des Angesichts und in der Gestalt die Nichte dir und der Neffe mir gleicht. Der Graf Arkan hat ihn neulich für mich gehalten. Wenn da nicht der Finger des Himmels ist, wo ist er dann noch? Und gerade eine Eingebung des Himmels könnte es auch sein, daß du die verwaisten Kinder zuerst in deinem Schlosse Biberau erzogen hast, daß dann der Knabe bei mir und das Mädchen bei dir war, und daß in uns der nämliche Gedanke entstand, sie einmal miteinander zu verheiraten, welchen Gedanken wir lange heimlich trugen, ehe wir ihn einander mitteilten. (676)

Und die Tante bestätigt:

Wunderbar sind die Namen der Kinder, wunderbar ihr gleicher Altersunterschied, wunderbar die Verhältnisse, die sie zu uns gebracht haben, wunderbar ihre Ähnlichkeit mit uns, und am wunderbarsten, daß wir beide unabhängig von einander den Gedanken ihrer Verehelichung faßten. (677)

All die aufgezählten Indizien aber beweisen das, was sie beweisen sollen, nur unter der ungenannten Voraussetzung, daß die Geschwister füreinander bestimmt sind oder es eigentlich wären. Nur so sind die von den Geschwistern als "Zeichen" (682) aufgenommenen Verdoppelungen eine Vorausbedeutung auf die Liebesbeziehung der Jungen. Nur unter der Prämisse des geistigen Inzests der Alten - ihre Begrüßungsküsse "auf den Mund" (667), denen der Verlobungskuß der Jüngeren "auf den Mund" (727) korrespondiert, sind dessen gestisches Äquivalent - kann die behauptete Doppelgängerschaft, die sich über Namen, Aussehen, Gebahren bis hin zur Gesundheit erstreckt, als Omen einer künftigen Liebe gelten. Die Affinität der jugendlichen Stellvertreter ist abgeleitet aus der Affinität, die zwischen den Geschwistern herrscht. So wie sich das Gespräch der Alten aus performatorischen Ritualen zusammensetzt - man grüßt, spricht Wünsche aus, eröffnet die Unterredung, beendigt sie, man entläßt sich -, so ist auch der Beschluß, die jüngeren Gerlint und Dietwin herbeizuzitieren, sie in die Textsphäre hineinzuziehen, das heißt die das weitere Geschehen bestimmende Parallelkonstruktion einzurichten, eine Art performatorischer Akt. Die Adoptivkinder treten von Anfang an in Funktion zur Sprache der Älteren auf. Ihr weiteres Tun hat substitutiven Charakter.

Was die Geschwister nicht aussprechen und was dennoch wie durch einen Fernsteuerungsmechanismus ihr Verhalten bestimmt, entspräche nach der Privatphilosophie des Oheims der ersten von drei möglichen Stationen seelischer Entwicklung. "Unser Leben hat drei Abteilungen. In der ersten Abteilung herrscht die Heftigkeit, dann kommen allerlei Einbildungen, und dann erscheint eine große Sanftmut und Gutmütigkeit, die bis in das hohe Alter andauert” 
(676f.). Irrtümlich glauben die Geschwister, nach dem militärischen Ausdruck des Oheims, "endlich in die dritte Abteilung eingerückt zu sein" (677). Ihr Weg der Versagung hat indessen ein letztes Mal das Stadium der Illusionen zu durchqueren, die sich aus ihrem noch wachen Verlangen speisen. Dem entspricht im Handlungsschema die Verkreuzung der Beziehungen.

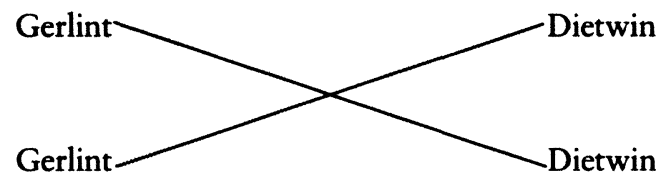

In dieser Beziehungsfigur begegnet das Begehren der Älteren dem der Jüngeren auf halbem Weg. Denn spiegelbildlich zu ihren Vorbildern suchen auch Nichte und Neffe, wie gewissen, von den Adressaten wohlbemerkten Nuancen zu entnehmen ist, durch Hinwendung zu den Ersatzeltern ihre wechselseitige unausgesprochene Neigung umzuleiten. Die doppelte Figurenkonstellation gibt den Projektionen des Begehrens freies Feld. Die Figuren selbst verständigen sich darüber in kryptischen Wendungen. Gerlint betet und schreibt ihr Gebet der Tante auf, “daß ein Übel, daß dir droht, lieber auf mich geleitet werde” (680), und öffnet damit - nirgends ist später explizit von irgendeinem Úbel die Rede der Inzestübertragung den Weg. In humoristischer Verbrämung gestehen sich auch die Männer solches Verlangen zu, etwa wenn nach allseitigen Liebesbezeugungen Dietwin zu Dietwin sagt: “du... mußt dann die Tante oder mich heiraten" (684). Dabei neutralisiert die Personensymmetrie auf geschickte Weise (und zwar wiederum durch Verdoppelung) das Familiendreieck Freudscher Art, so wie sie durch die indirekten Abstammungsverhältnisse gleichzeitig Vater/ Mutter-Konflikte ausspart ${ }^{24}$ und die Verwandtenehe zwischen den Kindern ermöglicht. Die konstruierte Ausgangssituation des Textes erfüllt poetologisch wie psychoökonomisch die Funktion, daß tabuierte Formen des Begehrens in der nötigen Latenz literarisch durchführbar werden. Das Aufschreiben bringt gerade das zur Darstellung, was es verbergen will, sich aber als Gegenstand durch die Prämissen der Handlung vorab gesichert hat.

Der weitere Gang der Ereignisse weist den Verdacht der Alten als Fehlleistung aus. Sie halten projektiv für eine gedankliche Abirrung ihrer Schutzbefohlenen, was ihre eigene gedankliche Abirrung ist. Sie denken sich in eine Verkreuzung der Neigungen hinein, die beide jeweils mit dem Ebenbild des anderen verbände, in der das Inzestverlangen umgewandelt würde in zwei "schiefe" (723), aber eben noch legitimierbare Beziehungen. Sofern die jüngeren Dietwin und Gerlint symbolische Repräsentanten der Geschwister sind, könnte gegenüber

\footnotetext{
${ }^{24}$ Die Genealogie des Hauses von der Weiden ähnelt dabei auf frappante Weise der des Hauses Donald Duck. Hier wie dort wird jeglicher Anklang an den auch nur familiären Vollzug von Sexualität ausgeklammert, indem die Fortpflanzung auf dem Weg der Neffengenese geschieht.
} 
dem unmittelbaren und reziproken Liebesimpuls von einer Umleitung des Begehrens in zwei sich ergänzende halbsymbolische Akte der Befriedigung gesprochen werden.

Zentrale Metapher der Beziehungen im Personenviereck sind die beiden Porträts im Schloßsaal. In ihrer ursprünglichen Bestimmung zeigen sie die Geschwister zu Zeiten jugendlicher Blüte. Das spricht die ausschließliche Zusammengehörigkeit beider deutlich genug aus, denn es wäre plausibler gewesen, hätte die Tante sich in ihrem Schloß an der Seite des einstigen Gatten verewigt sehen wollen, von dem indessen kein Bild erwähnt wird. ${ }^{25}$ Im Fortgang der Geschichte fungieren diese Porträts als Vehikel der Verwechslung. Denn während die jüngeren Gerlint und Dietwin sich selbst in den Jugendbildern ihrer Ersatzeltern wiedererkennen, schließen die Geschwister von deren häufigen Besuchen im Schloßsaal auf entflammte Neigungen zu sich. Sie mißachten bei diesem Fehlschluß den Zeitabstand zwischen Bildern und abgebildeten Personen. In Stifters Sprache heißt das, daß sie sich ihres Alters nicht hinreichend bewußt sind, daß sie das Jenseits des Verlangens noch nicht erreicht haben, das sie von sich fordern. Man könnte unterstellen, sie seien noch immer wechselseitig ins Ju-

${ }^{25}$ Und dies, obwohl Gerlint geschworen hat, ihn niemals zu vergessen und zeitlebens Trauer um ihn zu tragen. Der "arme Erwin" (679), wie die Tante ihren verblichenen Gemahl zu nennen pflegt, ist die sonderbarste Randfigur dieser an Sonderbarem durchaus nicht armen Erzählung. Ein höchst rätselhafter Passus läßt in einem echt viktorianischen Bogen der Umschreibung auf Nichtvollzug dieser Ehe schließen. Nachdem die Geschwister sich im Gespräch ihrer Einigkeit darüber versichert haben, daß Herrschsucht und Widerspruch Anzeichen von Leidenschaft seien, heißt es weiter:

“'Du hast ja auch an Erwin Erfahrungen gemacht,' sagte Dietwin.

'Ach der arme Erwin hat nie widersprochen, er hat die Mondnächte geliebt, und ist in solchen oft sehr lange in den Gängen unseres Gartens herum gewandelt,' erwiderte Gerlint.

'Dietwin wird stürmischer verfahren,' sagte der Bruder'” (679).

Sollte man darin eine Verrätselung der Unberührtheit der Tante lesen dürfen, so wäre die Entsprechung beim Bruder in seiner Äußerung zu suchen, er dürfe die Nichte schon deshalb nicht an sich binden, weil er ein "Knasterbart" sei, "sie käme dahinter, und es würde sie gereuen" (722). Der Text besitzt unzählige solcher Passagen, die, wenn man sie nicht ohnehin überliest, stets noch mit einiger Gewalt eine konventionelle Lesart suggerieren, aber im Gesamtzusammenhang höchst enigmatische Anrührungen der Angstzone des Sexuellen darstellen.

Das Hintergründige und Hinterhältige der Erzählung ist ihre nahegelegte, bei flüchtigem Lesen leicht in den Vordergrund tretende motivische Banalität, die erst wörtlich genommen ihre Geheimnisse zeigt. Was sich in dem Satz "Dietwin, ich kann es nicht ertragen, wenn dein Auge auf ein Weib blickt" (727) als pure Eifersucht liest, ist vielmehr Annihilation des Körperlichen. Der auf Eifersuchtstiraden kulturell konditionierte Leser assoziiert spontan ein fehlendes Wort hinzu und vermutet den Blick auf das 'andere Weib,' von dem der Text auch, aber keineswegs ausschließlich spricht. Für Stifters Figuren, die Anschauen mit erotischer Attraktion verbinden (719 u.a.), ist einzig der Blick auf das "Gattin" gewordene Weib legitim (727). 
gendbild des anderen verliebt und projizierten ihre Verliebtheit auf die Adoptivkinder. Das Kunstsymbol erwirkt eine semantische Offenheit, einen Interpretationsspielraum, der nicht freie Einsicht, sondern Verfehlung produziert ${ }^{26}$, wie überhaupt bei Stifter ein eigentümlicher Automatismus zwischen Freiheit und Versagen besteht.

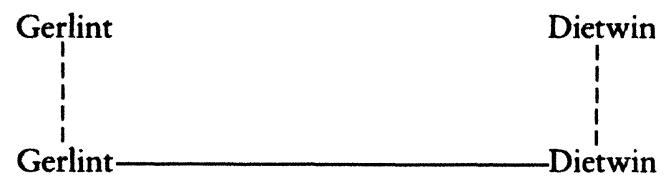

Erst der endgültige Entsagungsschritt der Älteren, ihr Plan, sich durch eine Reise der Dynamik des Verlangens zu entziehen, gibt den Weg zur Vereinigung von Neffe und Nichte frei. Erst der vollständige Verzicht noch auf den Gedanken an eigene Wunscherfüllung erlaubt Wunscherfüllung in der Form symbolischer Repräsentanz. ${ }^{27}$ Das Inzestverlangen wird durch Verschiebung auf die Ebene einer Stellvertreterhandlung zugleich gestillt und ausgeschlossen; die Geschwisterliebe, anfangs ein gewissermaßen noch gemischtes und nicht ausreichend geläutertes Gefühl, tritt in die beiden rechtmäßigen Komponenten reiner geschwisterlicher Altersbeziehung einerseits, die Ehe andererseits auseinander. Durch die Verdoppelung der Personen schafft Stifter einen Modus, Erfüllung und Versagung erzählerisch zu deckungsgleichen Vorgängen zu machen. Dahinter verbirgt sich als unausgesprochenes Fazit eine moralische Paradoxie: Glück, das für sich selbst verwirklichen zu wollen, ein Verbrechen gewesen wäre, kann erst durch Abtretung zum eigenen werden. Die Alten zitieren ihre Ebenbilder herbei, damit diese ausführen, was ihnen verwehrt ist, und dem Auszuführenden zugleich Regularität verleihen. Das Doppelgängermotiv, traditionell zum Zeichen der Angst und seelischen Zerrissenheit bestimmt, hat hier die Funktion der Beschwichtigung. Anomalie und Normalität, Verfehlung und richtiges Handeln kommen auf dem Weg der Personendoppelung zu einer Art Gleichnamigkeit.

Es entspricht Stifters Distanz zur Romantik, daß er den Doppelgänger, Symbolträger des Unheimlichen, seiner ängstlichen Implikationen entkleidet, um ihn als Vehikel eines harmonischen Gleichklangs zu verwenden. Trotzdem mag es verblüffen, wie leicht diese Transformation von Motiven der Angst in solche befriedeter Ordnung vonstatten geht. Zunächst rekurriert Stifters Aufstellung von doppelten Doppelgängern sicherlich auf eine Nebenlinie der mythologi-

${ }^{26}$ Einsicht trotz Verfehlung zu generieren, ist hingegen die Aufgabe des Kunstsymbols der Wablverwandtschaften, der Novelle von den Wunderlichen Nachbarskindern.

${ }^{27}$ Ein verräumlichtes Rudiment der Erfüllung des Inzestwunsches scheint noch die Tatsache zu sein, daß die Alten nach der Heirat näher beieinander sind: "so wären wir unter uns" (673). Zum Schluß ist das, was "beide so sehnlich wünschen, mit Gefügigkeit" erreicht (ebd.). 
schen Sinngebung des Motivs: wie Otto Rank einleuchtend vermutet, ist der Doppelgänger im "primitiven Narzißmus" "nichts anderes als eine Art des Unsterblichkeitsglaubens, der die Macht des Todes energisch dementiert." 28 Darüberhinaus sei die Inkarnation eines zweiten, differenzlosen Ichs - die Parallelen zu Stifter sind fast allzu deutlich - eine Angstreaktion auf die "Bedrohung des Narzißmus durch die Geschlechtsliebe" (Rank, S. 116). Monomanische Subjektivität schützt sich - bei Stifter immer im Bewußtsein der eigenen Hypertrophie - gegen Bedrohungen ihrer selbst durch Spaltungsmechanismen: "so kommt es," schließt Rank seine Betrachtung, "daß der die narzißtische Selbstliebe verkörpernde Doppelgänger gerade zum Rivalen in der Geschlechtsliebe werden muß oder daß er, ursprünglich als Wunschabwehr des gefürchteten ewigen Unterganges geschaffen, im Aberglauben als Todesbote wiederkehrt" (Rank, S. 117).

Aus der Sicht Freuds wäre das ganze Inventar des Stifterschen Textes ein Fundus von Unheimlichkeit; und doch drängt sich eigenartigerweise im Frommen Spruch diese Reaktion niemals auf. In seiner Untersuchung über Das Unheimliche, die sich weitestgehend auf ästhetische Beobachtungen stützt, listet Freud folgende Emanationen der Angst auf:

das Doppelgängertum in allen seinen Abstufungen und Ausbildungen, also das Auftreten von Personen, die wegen ihrer Erscheinung für identisch gehalten werden müssen, die Steigerung dieses Verhältnisses durch Uberspringen seelischer Vorgänge von einer Person auf die andere..., so daß der eine das Wissen, Fühlen und Erleben des anderen mitbesitzt, die Identifizierung mit einer anderen Person, also Ich-Verdoppelung, Ich-Teilung, IchVertauschung - und endlich die beständige Wiederkehr des Gleichen, die Wiederholung der nämlichen Gesichtszüge, Charaktere, Schicksale, verbrecherischen Taten, ja der Namen durch mehrere aufeinanderfolgende Generationen. ${ }^{29}$

Weiterhin "Das merkwürdige Zusammentreffen von Wunsch und Erfüllung, die rätselhafteste Wiederholung ähnlicher Erlebnisse an demselben Ort oder zum gleichen Datum" (Freud, S. 262). Was sich wie ein Pandämonium der Kunstmittel des Frommen Spruches liest, ist diesem in der Wirkung diametral entgegengesetzt. Die Zeichen des Schreckens, von Freud zusammengestellt, fungieren bei

\footnotetext{
28 Otto Rank, Der Doppelgänger (1925; zuerst 1914), S. 115. Im Stifterschen Text wird eine solche Deutung nahegelegt durch den naheliegenden, aber gleichwohl nur als Möglichkeit angesprochenen Gedanken der Geschwister, daß sie "früher sterben können als Dietwin und Gerlint" (673), der auch die Heirat der Jungen zu legitimieren hat, auf daß "sie mächtig und tüchtig und reich" seien "in undenkliche Zeiten hinein" (ebd.).

Zu Rank und zur kulturellen Modifikation des Doppelgängertums vgl. Friedrich A. Kittler, "Romantik-Psychoanalyse-Film: Eine Doppelgängergeschichte," in Hörisch / Tholen (Hrsg.), Eingebildete Texte (1985), S. 118-35.

${ }^{29}$ Siegmund Freud, Das Unheimliche, in Gesammelte Werke, Londoner Ausgabe (1955; zuerst 1919), S. 227-268, 246.
} 
Stifter als Indizes der Konkordanz. ${ }^{30}$ Umgekehrt wird auf diese Weise die Harmonie in ein direktes Abhängigkeitsverhältnis zum Schrecken gesetzt. Gegen die Romantik des Schreckens errichtet Stifter einen Schrecken der Harmonie.

IV.

Es ist inzwischen ein gängiger Topos, daß das dezidiert glückliche Ende, zu dem vom Nachsommer an alle Dichtungen Stifters finden, um den Preis rigoroser Verzichtsleistungen erreicht wird, die vorzugsweise, wie die Gestalt Heinrich Drendorfs illustriert, als stillschweigende Voraussetzungen der Mechanik des Gelingens in den Texten zugrundegelegt sind. Zumal der späte Stifter scheint von der Bemühung durchdrungen gewesen zu sein, seiner Kunst, die durchweg Opfergänge darstellt, den sichtbaren Opfercharakter zu nehmen. Das Spiel der Repräsentanzen, das er im Frommen Spruch einrichtet, hat exakt diese Funktion. Daß es kein Glück außerhalb des vollständigen Vorweg-Verzichts auf Glücksverwirklichung gibt, diese sublime Botschaft teilt die Erzählung mit den meisten ihrer Vorgängerinnen, und ebenso reproduziert sie das bei Stifter häufig ausgelegte Generationenschema, nach dem den Jüngeren die emotionslose Ausführung dessen vorbehalten bleibt, woran die Eltern in ihrer Heftigkeit scheiterten. Entschiedener aber als zuvor versucht Stifter in seiner letzten Erzählung, das Aufbrechen einer moralischen Differenz zwischen Weg und Ziel, Entbehrung und anschließendem Lohn zu unterdrücken. Das Verlangen wird nicht bloß sanktioniert, sondern gewissermaßen begnadigt in dem Moment, in dem es endgültig erlischt. ${ }^{31}$ Anstrengung und Bitterkeit des Verzichts, wie alle Manifestationen von Negativität, sollen nicht vorhanden sein. Nichts soll der Totalität richtigen Lebens geopfert worden sein und damit ihren Begriff gefährden. Es kann Stifter deshalb nicht darum gehen, einen moralischen Werdegang, nach

\footnotetext{
${ }^{30}$ Freud hat diese Möglichkeit für den Fall in Betracht gezogen, daß der Mensch alle animistischen Vorstellungen "gründlich und endgültig erledigt" habe (S. 270). In Anbetracht des Abdias, des Anfangs von Brigitta oder des Berichts Aus dem bairischen Walde läßt sich dies für Stifter keinesfalls behaupten. Vielmehr internalisiert Stifter die kulturellen Ängste so total, daß sie sich am Objekt nicht mehr zu entzünden scheinen.

Gegenüber der Beherrschung der Angst bedeuten Stifters späte Texte und Freuds theoretische Grenzbegehungen gleichlautende Lösungsversuche. Hier wie dort dienen Dichten oder Denken zur Austreibung der chimärischen Voraussetzungen des Bewußtseins.

${ }^{31}$ So stellt es eine Fehlinterpretation dar, wenn Wildbolz 1976 (Anm. 13), S. 136, den Frommen Spruch als eine "Rückkehr zur Subjektivität" darstellt. Entsprechendes gilt für Ursula Naumann, Adalbert Stifter (1979), die bemerkt zu haben glaubt, daß sich Stifter "darum bemüht, etwas von der verlorenen bzw. aufgegebenen Spontaneität der Anfänge zurückzugewinnen” (S. 71). Ungestüm und latente Lèidenschaft können die späten Texte nur deshalb erneut thematisieren, weil Stifter eine Operation gefunden zu haben glaubt, die auch das Verlangen in den Kosmos der Versagung integriert.
} 
dem Modell der Biographie, sprachlich zu entwickeln. Die statthabende Entwicklung darf vielmehr nur Selbstentfaltung einer schmerzlosen Vollkommenheit sein und dient ihrer epischen Präsentation. So ist auch das Ende der Geschichte keine Erfüllung in dem Sinn, daß etwas Ungelöstes gelöst worden wäre. Was als Läuterung der Liebe zwischen den jugendlichen Verwandten einen prozessualen Charakter vorgibt, ist präziser bestimmt eher ein Vorgang wachsender sprachlicher Entbergung einer vorab festliegenden Disposition. Die jungen Leute erscheinen von Anfang an in die Konventionen der Alten eingefügt, von ihrer Heftigkeit werden nur in den Gesprächen Indizien gegeben, die uneingestandene Neigung wird an Symbolen festgehalten, und zum Gegenstand offener Aussprache kann sie erst werden, als sie sich auf die Temperatur des Gesamttextes herabgestimmt hat. Die jungen Gerlint und Dietwin finden in dem Augenblick zueinander, in dem ihre Liebe ihrerseits die Gestalt einer leidenschaftslosen Geschwisterliebe angenommen hat. ${ }^{32}$ Die "dritte Abteilung," in die schließlich alle Personen einrücken, ist ihnen vorgegeben gewesen, der Weg dorthin war nur ein scheinbarer, sozusagen rhetorisch abzuschreitender Weg. Diese Mechanik einer sich retrospektiv selbst einholenden Vollkommenheit

32 Der Text führt zwei Paare vor, die angstvoll gebannt das Gebiet der Sexualität umstellen, jene Zone unaussprechlicher Neigungen, die mit dem Geltungsbereich des titelgebenden Spruches, daß "Ehen in dem Himmel geschlossen werden" (passim), zusammenfällt. Die Älteren suchen sich dem mittleren Lebensalter der sexuellen Reife durch eine Art Frühvergreisung zu entziehen. Der 44jährigen Tante beliebt es, sich eine "alte Frau" (683) zu nennen. In der Nachfolge von Hein (Anm. 4), der von den "beiden an der Grenze des Greisentums angelangten Geschwister[n]" (Hein, S. 826) spricht, ist die Forschung in die Falle dieser poetischen Operation Stifters gegangen.

Die beiden Jüngeren hingegen zeigen Anzeichen der Regression. Sie wollen "in der Liebe wetteifern" (727) und so in den Verhaltensweisen ihrer Jugend befangen bleiben. Gerlint die Jüngere betont den Wunsch, ein Kind bleiben zu wollen, niemals die mütterliche Tante verlassen zu müssen: "Und so nimm mich, liebe Mutter, und lasse mich bei dir, und rede von keiner Zeit [!], in der ich dich verlassen soll" (691).

Es sei ergänzend angemerkt, daß die endlich erfolgende Heirat weniger aus einer Idee fruchtbarer Erneuerung als aus dem Motiv der Schließung der Familieneinheit und des Stammesgebietes heraus gewünscht und angebahnt wird (673). Die Ordnung der dargestellten Welt und des Gutes ("Wir sind beide nun gerundet" [672f]) riegelt sich auch darin in sich selbst ab, daß sie mehr einen Abschluß als eine Zukunft schafft. Der Stamm derer von der Weiden ist ein absterbender Stamm. Er wird seine Familieneinheit nicht bewahren können, es sei denn durch den paradoxen Akt der größten Unreinheit, den Inzest, der somit wiederum am Horizont des Erzählten auftaucht.

Zur Funktion der Familie bei Stifter vgl. u. a. Friedrich Aspetsberger, "Der Groß-Sprecher Heinrich Drendorf," VASILO, 32 (1983), 179-219, insbesondere S. 212ff. Trotz des interessanten Titels nur wenig Substantielles bietet Rosemarie Hunter, "Kinderlosigkeit und Eschatologie bei Stifter," Neophilologos, 57 (1973), 274-83. Zur wiederkehrenden Geschlossenheit der Handlungen bei Stifter vgl. Gerhard Plumpe, "Zyklik als Anschauungsform historischer Zeit," in Jürgen Link et.al. (Hrsg.), Bewegung und Stillstand (1984), S.201-25. 
wird wiederum in dem Motiv der Gemälde im Saal gespiegelt. Die Gemälde verkörpern eine sistierte, ewige Zeit. Ursprünglich Abbildungen der Geschwister, hatten sie durch das Fortschreiten der empirischen Zeit eine doppelte Bedeutung erhalten. Die Aufhebung der entstandenen Differenz aber wird allein durch die Tatsache ermöglicht, daß Altes und Neues in Wahrheit nicht differieren, daß die Jüngeren die Wiederholung der Älteren sind und folglich die Kluft der Zeit durch die zyklische Anlage des Textes annulliert ist. Ordnung stellt sich nicht im und durch den Text, nicht prozessual, sondern kraft seiner Konstruktionsweise her. Sie stellt sich her, weil sie immer bestand; die Textanlage ist nicht ihr Medium, ihr Verhandlungsort, sondern ihr Träger. Ein Problem kommt nicht zur Lösung, es verschwindet vielmehr aufgrund der Tatsache, daß es nicht existierte. Die aufgebrochene Doppeldeutigkeit der Bilder wird dadurch beglichen, daß diese nur die Zeitlosigkeit des identisch Wiederkehrendén porträtieren. Fernab jeder Plausibilität, die sich auf die Natur der Dinge beriefe, erweist sich die Richtigkeit der Welt als ein synthetisches Texterzeugnis. Die Gemälde, die nach ihrer dritten Bestimmung die Zusammengehörigkeit der jungen Leute bezeichnen, verhalten sich zur Handlung wie ein semantischer Kommentar. Und so kann man analog zur symbolischen Exekution des Inzests auf Handlungsebene von einem Inzest zwischen Zeichen und Bedeutung sprechen, der die entstandene semantische Differenz - zwischen gleichem Namen, gleichem Außeren, gleichem Wesen - nicht sowohl überwindet als ihrer Scheinhaftigkeit überführt. Die Handlung gibt sich als eine Art aufgeblasener Stillstand zu erkennen, der allein durch Zeitstreckung, semantisch dysfunktionale Redundanz und durch die rhetorische Einlegung eines epischen Mindestgefälles an ihrer Implosion gehindert wird. Wie auf fiktionaler Ebene der Weg vom unaussprechlichen Inzestverlangen zu dessen symbolischer Exekution beschrieben wird und mithin nichts als die Einkleidung eines Prozesses sprachlicher Substitution und Legitimierung darstellt, so wird analog auf dem Niveau des Schreibens selbst die Sprachlosigkeit dessen, was nicht im Text sein darf, in eine extensive textuelle Stummheit überführt, die die Stummheit der Ordnung ist.

V.

Für den Schulmeister, wie Stifter auch einer war, gehören zu einem Text ein Schauplatz und eine Handlung, beide sind zu beschreiben. "Nachdem wir nun den Schauplatz beschrieben haben, gehen wir zu dem über, was sich dort zugetragen hat" heißt ein in seiner Naivität beglückender Satz aus dem Beschriebenen Tännling. ${ }^{33}$ Unser Verfahren wählt die umgekehrte Reihenfolge, da der Fromme Spruch nur Rudimente eines Schauplatzes aufzuweisen scheint. Stifter

33 STU 1132. 
liebt es, seine Erzählungen durch ein Tableau zu eröffnen, in das er die Figuren wie Versatzstücke der Räumlichkeit hineinstellt. In der letzten Erzählung ist der Handlungsort ein "Gut" (665). Es kann auch als "Schloß" bezeichnet werden, und in seinem Innern gibt es ein "Prunkzimmer" oder "Saal," einen "hohen Schloßgang" mit "großen Eichentüren," Wohngemächer mit jeweils "zwei wohlbestellten Zimmern," eine "große Schloßtreppe," einen Garten, ein "Haupttor." Mehr erfahren wir nicht. ${ }^{34}$ Auch dies nur dann, wenn die Darstellung ein Minimum an Lokalisation oder Blickverweildauer erfordert. Die umgebende Landschaft spielt mit einer noch zu behandelnden Ausnahme so gut wie gar keine Rolle. Für Stifters verräumlichtes Denken, ${ }^{35}$ das der Raumeinrichtung stets höchste symbolische Valenz zuschreibt, ist eine derart restriktive Symbolökonomie bemerkenswert. Nicht nur daß er sich mit einer Symbolik des Interieurs begnügt; die entfaltete Zeichenwelt selbst gestaltet sich zu einem geschlossenen Raum. Der Abschneidung der Referenzen nach außen entspricht eine absolute Determination und Funktionalisierung der Sinnverweise im Innern des Sprachduktus. An die Stelle des natürlichen Prospekts, den die früheren Erzählungen mit schöner Regelmäßigkeit eingangs exponiert hatten, tritt das von der Sprechweise der Figuren selbst generierte Zeremoniell. Die sprachlichen Verkehrsfor-

${ }^{34}$ Eine Ausnahme macht hierbei die Zimmereinrichtung der Nichte (707f). Bei der Entleerung ihres Zimmers von Spiegeln und pittoreskem Nippes dreht Gerlint gleichsam den historischen Prozeß um, der vom leeren Biedermeierraum (vgl. Schwinds Gemälde Morgenstunde, an das Gerlints Raum denken läßt) zum angefüllten historistischen Interieur der zweiten Jahrhunderthälfte führt. Indem sie die Vorhänge entfernt, um "in den Himmel sehen" zu können (707), setzt sie sich auch in Gegensatz zu ihrem Autor, der nach Roseggers Bericht die Fenster verdunkelte, um sich sprachlich nach draußen versetzen zu können: "er ließ die Fensterrollen nieder. Und nur wir eingehüllt waren und keinen Sommer mehr sahen, hub er an, recht von dem Sommer zu sprechen" (zit. n. Hein [Anm. 4], S. 786; die Rede ist von Stifters letztem Sommer 1867). Solches ist freilich zu dieser Zeit schon ein festes Emblem dichterischer Genialität geworden. So bemerkt Storm anläßlich eines Besuches beim alten Mörike: "Mörike machte, obwohl es noch hell war, die Jalousien dicht, ließ eine Lampe bringen"; dann fängt er an vorzulesen (Brief an Hartmuth Brinckmann, 28.9.1855).

Gerlint entfernt auch alle Kunstgegenstände aus ihrem Zimmer, verschließt den Flügel, statt "Gerätschaften zur weiblichen Arbeit" stellt sie Pflanzen auf. Mit den Kunstwerken entfernt sie die ihnen eigene semantische Offenheit, -mit dem Flügel verschließt sie die Möglichkeit mittelbarer Expression, mit den Spiegeln verschwindet die Möglichkeit zur Selbstbetrachtung, produktive Arbeit leistet Gerlint innerhalb und außerhalb des Hauses nur an "Gewächsen." Die meisten verbleiben wie der verschlossene Flügel im Zimmer. Die Aphasieleistung hat sichtbar zu bleiben.

${ }^{35}$ Untersuchungen zu Stifters Raumerfahrung sind immer wieder aufschlußreich. Vgl. Hans D. Irmscher, Adalbert Stifter: Wirklichkeitserfabrung und gegenständliche Darstellung (1971); sowie Bruno Hillebrand, Mensch und Raum im Roman: Studien zu Keller, Stifter, Fontane (1971). Steffen (Anm. 1) deutet bereits das erste Treffen der Geschwister "in der Mitte des Gemaches" (665) als bestimmend auch für das Verhalten der Generationen zueinander. 
men nehmen in der Exposition den breitesten Raum ein. Aus dem Zeremoniell (nach dem Namen ist "Gepflogenheit" das erste Substantiv der Erzählung) werden Topographie, Ambiente, Handlung und der größte Teil der auftretenden Personen geboren. Die gemessenen Formeln der beiden Alten eröffnen den Lebensraum und entlassen ihn fortan nicht mehr aus ihrer Kontrolle. Ja selbst die Protagonisten unterliegen den von ihnen eingeführten semantischen Restriktionen. Auf Signifikanzen zu warten, oder die bestehenden richtig auszudeuten, ist ihre einzige Beschäftigung. "Ist das nicht wieder ein Zeichen?" fragt bang erwartungsvoll der Oheim (682) und umschreibt damit den detektivischen Charakter, den ihr zwischenmenschlicher Umgang angenommen hat. Aus der Verweigerung "sinnlicher Zeichen" (675) entsteht umgekehrt die anfängliche und aufzulösende Dynamik der Ereignisse. Der Text erhebt sich nicht über das Protokoll und die von diesem produzierten Unwägbarkeiten, er statuiert keine Gewißheit, die außerhalb der protokollierten Rituale läge.

Mit wenigen Worten ließen sich die im Frommen Spruch vorkommenden Gegenstände und Handlungen versammeln und in ihrem entweder nicht vorhandenen oder explizit und restriktiv eingesetzten semantischen Wert auflisten. Kein einziges von ihnen scheint zufällig. Entweder sind sie unabdingbares Material für ein Mindestmaß an Welthaltigkeit, oder aber sie schließen sich in einem Zirkel immanenter Stimmigkeit zusammen, bilden ein Koordinatensystem "sinniger” Bezüge. Wenn der Beginn der Erzählung in ein Agglomerat von Zeichen einzuführen scheint, so gilt doch für diese, was Dietwin der Ältere in der Einleitungszeremonie als "vortrefflich" bezeichnet: sie sind nämlich "ohne Bedeutung" (666). Nichts an ihnen als ihr doppeltes Vorkommen ist noch eine Funktion der erzählerischen Ökonomie.

Am 24.4. ${ }^{36}$ reitet Dietwin in das Gut seiner Schwester ein. Er kommt mit 2 Dienern, bezieht 2 "wohlbestellte Zimmer," während seine 2 Schimmel versorgt werden. Ihn erwarten 2 schwarzgekleidete Damen hinter einer Flügeltür (wohl mit 2 Flügeln). Eine der Damen, die Schwester, empfängt ihn in der "Mitte" des Saales. 2 Küsse werden gewechselt, 2 weitere Diener rücken einen Armstuhl zurecht, worauf sich "beide" Protagonisten voreinander verneigen und ein doppeltes Sprachspiel beginnt, das sich bereits eine Seite später wiederholt: "Sei gegrüßt, Dietwin." - “Sei gegrüßt, Gerlint” (alles 665). Die Variationsreihe von doppelten Handlungen; Menschen, Gesten und Dingen endet konsequent im

${ }^{36}$ Das Desinteresse Stifters an einer glaubwürdigen Handlungsführung geht so weit, daß es zugunsten einer kohärenten Symbolwirtschaft sogar zu gröbsten Fehlleistungen kommt: obwohl die Eingangshandlung den 44. respektive 50. Geburtstag der Geschwister zweifelsfrei auf den Folgetag, den 25.4. legt, wird später der 24.4. gefeiert (710 und 715). Das notwendige gemächliche Verstreichen der Zeit (Ankunft einen Tag vor dem Fest) koexistiert trotz logischer Unsinnigkeit mit dem zahlensymbolisch notwendigen Datum des 24.4., das nur aus Zweien und Vieren besteht. Die Forschung ist gegenüber solchen Feinheiten des Arrangements im Stifterschen Text bisher blind gewesen. 
äquivoken double-talk der Geschwister. Es ist, als ob Stifter Reime aus Algebra herstellen wollte, weil er die Unreinheit der ungeraden Zahlen fürchtet. ${ }^{37}$ Das Zeremoniell hat keinen anderen Sinn als die Zelebration seiner Reinheit. Es arbeitet als poetologische Vakuumpumpe der Bedeutungen, indem es jede mögliche emotionale Dynamik, alle Vieldeutigkeiten in Äquivalenzzustände überführt und sicherstellt. Verdoppelungen allenthalben: in der Rede und in ihren Gegenständen, bei Personen, Namen, Pferden, Kühen, Weizenfeldern und Gefühlen ebenso wie bei Dienern, Rosengärten, Schlössern, Zimmern und Erinnerungen. Der Text, der gegenüber allen seinen Objekten die gleiche ahnungslose Äußerlichkeit behaupten will, nimmt selbst die Struktur der von ihm referierten Zweiheit der Worte und Gedanken an.

Es lassen sich zwei Klassen von Symbolen unterscheiden. Die einen figurieren auf der Bühne des Geschehens als reine und nichtige Träger von Ausdehnung; sie zeigen kaum mehr vor als ihre quantitative Präsenz. Die anderen erfüllen eine dezidierte Ausdrucksfunktion für die Handlung, strahlen aber in keine weiteren Bedeutungsräume aus. Die doppelten Rosen, Kühe, Weizenfelder gehören zu ihnen. Durch sie rückt die Liebe der Jüngeren auf die Stufe der Metaphernbildung. Die Rosengärten - mehr eine Pracht der Namen als leibhaftiger Blumen, in deren Nomenklatur Stifter sich mit einer förmlichen Wollust ergeht - zeigen die Läuterung ihrer Liebe an. Weiter reicht ihr semantisches Dasein nicht; die Dinge gewinnen keine eigenständigen sinnlichen Qualitäten. Mit der Aufzucht zweier Paare makelloser Kühe setzen die Jungen ihren Willen ins Bild, am Ende einer Prozedur der Verähnlichung, die erst noch agonalen Charakter hat, in unbedingter Differenzlosigkeit zueinanderzufinden. Entsprechendes gilt für die Weizenfelder. Es ist dabei auffallend, wie sehr die rein symbolische Funktion der Zuchterfolge unterstrichen wird. Der Text nimmt große Unwahrscheinlichkeiten in Kauf (so etwa, daß man die Anlegung eines Weizenfeldes der Gutsfamilie verheimlichen könnte), um nur nicht das Moment realer Arbeit an diesen Tätigkeiten zur Erscheinung kommen zu lassen. Selbst diese noch handlungstragenden Symbole führen der Tendenz nach ein bloß nominales Dasein.

Noch weiter fortgeschritten ist die semantische Entleerung in den beschreibenden Passagen des Frommen Spruchs, deren reduktionistisches Verfahren dem des Zeremoniells logisch entspricht. Die äußerste Reduktion kohärenten Erzählens ist die geometrische Ortsbestimmung. Gleichzeitig bildet sie, weil inhaltsfrei, einen Wunschtraum jeglicher Ordnung. Sie ist exakt, weil sie von der

${ }^{37}$ Sprachliche Reinlichkeit kommt übrigens auch darin zum Ausdruck, daß Ehen "in dem" und nicht "im" Himmel geschlossen werden (passim); die Zusammenziehung hätte wohl etwas Revoltierendes an sich. - Die Verdoppelung ist bereits seit längerem als Strukturprinzip von Stifters Dichtung ausgewiesen worden. Vgl. zu den Nachkommenschaften Ursula Mahlendorf, "Stifters Absage an die Kunst," in Goethezeit: Festschrift für Stuart Atkins, hrsg. G. Hoffmeister (1981), S. 369-83, S. 379ff; sowie Klaus Amann, "Zwei Thesen zu Stifters 'Nachsommer," VASILO, 31 (1982), 169-83, $177 \mathrm{f}$. 
Last befreit ist, mehr als sich selbst zu besagen. Sie bietet keinen Raum für Assoziationen.

Dann nahmen sie auf Stühlen, die in mehreren Kreisen herum standen, Platz, und es wurden nun Gespräche über verschiedene Gegenstände, und man teilte sich mit, was man der Mitteilung wert erachtete. (687)

Dem Dichter ist an der Situation hauptsächlich die Lage der Sitzgelegenheiten zueinander "der Mitteilung wert": die geometrische Abmessung von leeren Bedeutungen, die sich aus dem passivischen Selbstvollzug der Sprache im Text ("es wurden nun Gespräche") folgerichtig ergibt und das Vorgehen des ganzen Textes aufs genaueste widerspiegelt.

In der abendländischen Kulturgeschichte ist seit jeher die Geometrisierung ein Index reiner Ordnung. Sie funktioniert, betrifft sie nun barocke Gärten, ideale Städte, gebundene Sprache, hauptsächlich als formale Operation. Ihre Apotheose ist die Symmetrie. Stifter hat diese Symmetrie, wie es unsere Analyse der Handlung erbrachte, durchaus auf eine inhaltliche Ebene transformiert. Sein Ordnungsunterfangen gewinnt den Charakter einer totalitären Utopie, der architektonischen Symmetrieentwürfen nicht erst seit Thomas Morus, Ludwig XIV., Haussmann anhaftet und als literarische Technik scheinbar nicht zu adaptieren war. Er betreibt eine rigorose Haussmannisierung der Sprache und der Symbole. Die wichtigen verdoppelt er zur Wahrung der symmetrischen Anlage und schlägt ihnen große, gerade Fluchten durch die wuchernden, versteckten Bereiche freier Bedeutungsfluktuation. Das unhintergehbar Faktische einer im Habitus des Realismus auftretenden Erzählweise wird der Geometrisierung ebenso unterworfen wie die Umgangsformen und Kommunikationsrudimente der Personen und zuletzt die sie fixierende Sprache des Dichters. Ihr Ziel ist eine quasi kartographische Vernetzung von Sinnträgern, die entweder Leerstellen sind oder ihre semantische Konzession allein unter der Auflage absoluter Eindeutigkeit von der Zentralinstanz der Textökonomie her beziehen. Die Zeichen werden entweder streng kodifiziert oder mit Bedeutungsentzug geschlagen. In der abstrakten Geometrie der Darstellung erwirken selbst die Personen keine Diskontinuierlichkeit mehr. Sie sind durch nichts vom übrigen Rauminhalt unterschieden.

In dem Saale war ein kostbarer Teppich auf den Marmorfußboden gebreitet, auf dem Teppich stand ein sehr geräumiger rotseidener Armstuhl, und in dem Armstuhl saß in ihrem aschgrauen Seidenkleide Gerlint. $(667)^{38}$

Als logische Konsequenz einer Abfolge von Einrichtungsgegenständen erscheint

38 Ahnliche Spiele mit der absurden Ordnung der Welt hat - auf kongeniale Art Sergiu Leone zur Kennzeichnung der zynischen Gewaltverhältnisse im Wilden Westen verwendet. Wir zitieren nach dem Gedächtnis aus seinem Film Spiel mir das Lied vom Tod: "Ich habe drei Mäntel gesehen, in den Mänteln steckten drei Männer und in den Männern drei Kugeln.” 
der Mensch. Alles, was nur im Entferntesten ein freies Spiel symbolischer Bedeutungen und Assoziationen erzeugen könnte, ist aus der Schilderung verbannt. Der Text zieht es vor, nur von "verschiedenen Gegenständen" zu sprechen, statt ein Eigenleben der sinnlichen Details zu riskieren. Sein Phantasma ist die reine Monokausalität der Sinnverweise. Wo diese Operation undurchführbar erscheint, sucht die Textsprache ihre Signifikationen vollkommen zu unterbinden: über weite Strecken finden keine Interaktionen zwischen den Zeichen statt. Der Text neigt an solchen Stellen zum absoluten Zeichen, das nichts mehr, sei es denn sein eigenes Vorhandensein, repräsentiert. Die Sprachmaschine läuft leer und produziert - um eine Wendung von Deleuze/Guattari zu gebrauchen nur noch ihr eigenes Produzieren. ${ }^{39}$ Die Erwähnung von Gegenständen dient ausschließlich dazu, ihr ordnungsgemäßes Vorkommen zu konstatieren, und ist doch andererseits nichts weniger als zufälliges Beiwerk, hinter dem irgendeine Hauptsache sich verbirgt. Die Beschreibungen sind Additionen von Nomina. Die ihnen beigestellten Adjektive heben, da sie allgemeinster Art sind, diesen Ausdünnungsprozeß keineswegs auf, sondern intensivieren die Aussagelosigkeit der Gegenstände. Entsprechendes gilt für die Farbsymbolik: entweder ist sie ebenso monokausal wie banal determiniert oder unauflöslich nichtssagend. ${ }^{40}$ Immer von neuem wird so die hergebrachte Haltung "sinniger" Lektüre sabotiert.

An einer einzigen Stelle erhält im Frommen Spruch die Schilderung von Landschaft Gewicht. Nach ihrer Ankunft auf dem Schloß schreitet Gerlint dessen Umgebung und damit zugleich die Stätten ihrer Kindheit ab. Vor ihr geht der junge Dietwin den gleichen Weg. Der besichtigte Raum ist dabei keineswegs Medium einer wie auch immer gearteten Erfahrung. Die Jungen durchwandeln explizit nur das emotional längst abgesteckte Interieur ihrer Erinnerung. Zwar präsentiert sich ihnen die Landschaft - wie sie erst später wissen und wechselseitig voneinander erfahren werden - als Territorium ihrer seit langem schlummernden Liebe, doch ist auf dem Niveau der Schilderung jegliche Korrespondenz zwischen Gefühltem und Gesehenem, zwischen "Gehirn" (666) und Welt gekappt. ${ }^{41}$ Ihre Wahrnehmung ist stumme und bewußtlose Wiederholung. Ge-

${ }^{39}$ Solche paradoxen Formulierungen können sich freilich direkt auf Stifter berufen, der in den performatorischen Akten, dem Reden vom Reden, den leeren Vollzug einer Handlung als deren eigene Befriedigung feiert, um einen horror vacui sprachlich gleichzeitig zu benennen und zu verbrämen.

${ }^{40}$ Ersteres gilt für das "aschgraue" Trauerkleid Gerlints, letzteres für den "rotseidenen" Armstuhl. Solches wäre nicht weiter bemerkenswert, wenn nicht Sätze wie "Auf das Haupt wurde ein blaßgelber Strohhut gesetzt" (693) in ihrer Prononciertheit eine symbolische Lektüre - etwa im Sinn der roten und weißen Gegenstände im Beschriebenen Tännling oder der blauen Gewächse im Abdias - nahelegen würden.

${ }^{41}$ Derartige perspektivische Eingriffe in den Seelenhaushalt seiner Figuren, die ihm in jungen Jahren noch durchaus vertraut waren, unterläßt der alte Stifter. Seine Landschaften sind so ungerührt wie die Menschen, die sie durchmessen. 
genüber irgendeinem Neuen ist ihre Erfahrung der Außenwelt hermetisch abgeriegelt.

Gerlint besichtigt die Gegend. In perspektivischer Sukzession werden ihr und dem sie begleitenden Leser die Dinge ins Blickfeld gerückt. Erst stellt der Text die Gegenstände an ihren Platz, dann bezieht sich Gerlint motorisch und optisch auf sie. Schauplatz ist das schlichte Vorhandensein der Dinge, Handlung ihr stummes Durchschreiten. "Zuerst war ein dichtes Wäldchen von wilden Kastanien." Was macht Gerlint im Wäldchen? "Sie schritt durch das Wäldchen." Dann 'sind' da Gewächshäuser und Zwergobst, "Sie erwiderte freundlich den Gruß des Gärtners," da sind Obstbäume, "Sie ging durch den Wald dahin," schließlich eine einzelne Eiche, "Auf diese Eiche ging Gerlint zu" (alles 699).

Als sie sich ihr näherte, sah sie Dietwin, den jüngeren, von der Eiche weg gegen den Rand des Hanges gehen. Sie blieb ein Weilchen stehen. Dann ging sie wieder weiter gegen die Eiche. In einer angemessenen Entfernung von derselben blieb sie stehen ... und betrachtete den Baum. Sein Schaft ging schlank empor, und man hätte dessen Mächtigkeit nicht erkannt, wenn nicht von ihm die untersten Äste in der Dicke zweier Männer in die Breite gegangen wären.... Gerlint sah lange auf die Gestalt dieses Baumes. Dann ging sie in einem Kreise um ihn herum, und betrachtete ihn von allen Seiten. Als sie ihre Betrachtung geendigt hatte, ging sie langsam gegen den Rand der Höhe hinan. (699f.)

Der Symbolgehalt der beschriebenen Eiche liegt weniger in dem nur brachialanalytisch deutbaren, gleichwohl vorhandenen Assoziationsfeld eines "schlanken Schaftes," dessen Mächtigkeit nur auffällt, weil "Äste von der Dicke zweier Männer" (Dietwin \& Dietwin?) von ihm ausgehen. ${ }^{42}$ Für die beiden jungen Leute gehört der Baum zu den Erinnerungsmarken ihrer stillen Leidenschaft, und damit zu den latenten Zeichen der Liebe. Im einleitenden Gespräch der Alten klingt solches an, wobei die Eiche freilich nicht ausdrücklich erwähnt wird. $\mathrm{Zu}$ seiner notwendigen Lesart gelangt das Symbol Eiche erst, als sie in der Erkennungsszene gegen Ende der Geschichte per declarationem zum Indiz erotischer Affinität erklärt wird. Wie in einer Detektivgeschichte dreht sich alles darum, den Bedeutungsgehalt der feststellbaren Indizien in fortschreitender Untersuchung zu fixieren. Niemals geschieht in Stifters Erzählung, die das Gegenteil einer Novelle ist, weil sie keine überraschenden Wendungen kennt, etwas wirklich Neues: alte Fakten werden durch neue Rahmenbedingungen nur stets neu lesbar gemacht. Und es zeigt sich, daß die zeichenlesenden Personen wiederum nur das entdecken, was von vornherein feststand. Denn von Anfang an

\footnotetext{
42 So kommt Stifter gegen seinen Willen doch dazu, "lasterhafte Landschaften" zu zeichnen, was er in der Besprechung der Ausstellung des oberösterreichischen Kunstvereins im Oktober 1867, also zeitgleich mit dem Frommen Spruch, als höchste Perversion der französischen Kunst anprangert (SW, XIV, 217-31, 220). Vgl. hierzu Arno Schmidt, Nachwort zu Sitara und der Weg dorthin (1969), 244-61. Schmidt entdeckt auf Stifters Gemälden, "ohne dem Material die geringste Gewalt anzutun, eine Reihe von 20 Gliedern" (S. 257), findet die landschaftsschildernden Erzähltexte voll von "Organ-Abbildungen" (S. 260).
} 
hatte die Eiche als Wahrzeichen des Geschlechtes von der Weiden und seines Fortbestandes gegolten. Jeder der an Gerlint denke und den weithin sichtbaren Baum erblicke, sagt die Tante, werde "doppelt" an sie denken (721). Die jungen Leute, die wie unter einer Vorschrift der Unbewußtheit ihrer Liebe leben, machen sich diese Bestimmung erst am Ende zueigen. In der zweifachen und schließlich identischen Zuordnung des Wahrzeichens Eiche zur Okonomie des Stammeslebens und der Gefühle erschöpft sich deren semantischer Gehalt. Er wird im Text unter Vermeidung jeder enigmatischen Färbung ausdrücklich benannt. Mehr als etwas, was von Anfang an klar ist und am Ende zum Bewußtsein gelangt, soll das Zeichen nicht sein. ${ }^{43}$ Textdeutung kann und muß sich hier auf die Versammlung von Zitatstellen beschränken. Die Bedeutungshaftigkeit einzelner hervorgehobener Signifikate ist der Bedeutungsleere der anderen Nomina ähnlich.

Gerlints Blick ist nicht apperzeptiv, er hat kein synthetisches Vermögen, als sei sie selbst von der Stummheit der Dinge sprachlos gemacht. Sie antizipiert nichts, schaut nicht auf, blickt nicht zurück, scheint Dietwins dreimaliges Auftauchen auf dem Weg vor ihr auf eine völlig begriffslose Weise wahrzunehmen. Um sich den Umfang des Baumes zu vergegenwärtigen, muß sie um ihn herumgehen. So führt der Text räumlich noch einmal das Verhalten vor, das seine Protagonisten durch die gesamte Handlung an den Tag legen. Es findet keine Aneignung, keine Einverleibung, keine Interaktion mit den Dingen statt. Texttheoretisch entspricht die absolute semantische Kontrolle aller Sprachpartikel dem dargestellten Standard der Beherrschung der Natur. Das läßt sich durch einen Vergleich mit Goethes Wablverwandtschaften am deutlichsten erhellen. Dort sieht man die Personen mit Erschließungsarbeiten beschäftigt, sie verwandeln die Natur in den Park, legen Wege, Ruhesitze, Lustorte an. Gerlint dagegen bewegt sich durch einen längst erschlossenen Raum. Wohin immer sie kommt selbst am Ende eines steilen Pfades, dort also, wo die Metaphorik den Schritt ins Andere der Natur anzukündigen scheint -, findet sie "Tische und Stühle" (699) vor, die den musealen Charakter ihrer Blickwelt bestätigen. Gegenüber der Parklandschaft Goethes markiert Stifters späte Arbeit eine so weit fortgeschrittene Vergleichgültigung der Natur, daß diese weder Gefahr noch Versuchung noch Verheißung mehr in sich enthalten kann. Man bedenke, welche mythische Macht, sich den Kultivierungsarbeiten der Gutsbesitzer zu widersetzen, Goethe

${ }^{43}$ Auch dies ist neben der Informationsverweigerung, der fortlaufenden Uminterpretation von Indizien, des Verschwiegenen als Zentrum des Textes ein Signum des Detektivromans. Immerhin finden sich in Amalia Stifters Nachlaß der Bücher ihres Mannes sechs Bände Sue, zwei Bände Scott (SW, XXV, 408ff.). Hans D. Irmscher hat anläßlich des Nachsommer auf das Stifter eigenartigerweise nicht ferne Detektionsschema verwiesen ("Keller, Stifter und der Bildungsroman des 19. Jahrhunderts," in Handbuch des deutschen Romans, hrsg. Helmut Koopmann (1983), S. 370-94, S. 385). 
dem Teich zuerkannt hatte. Im Nachsommer ist ein See Gegenstand jahrelanger Vermessungsarbeiten. Im Frommen Spruch ist die Vermessung abgeschlossen.

Der Wald endete mit starken Stämmen an einem großen Teiche, der klares Wasser enthielt, und in dem Fische gehegt wurden. Gerlint ging an dem Saume des Wassers dahin in der Richtung gegen das Schloß zu. (701)

Von der ganzen Mythologie ist nur eine Art Positionsmarke, bestenfalls eine ferne symbolische Zitierung, übriggeblieben. Stifter will keine goetheanisch "incalculablen" Werke mehr produzieren. Der Teich ist nichts weiter als ein Teich, ein Zuchtbassin für Fische. Die Signifikanz der Signifikate geht der Tendenz nach in sich selbst auf. Die Banalität einer vollkommen unterworfenen Natur führt bruchlos in die Banalität ihrer Bezeichnungen hinüber. Die Sprache verharrt, nach Abschneidung ihres magischen Hinterlandes, zölibatär im Zivilisationskreis der Sprache; sie ist so impotent oder inzestuös wie der ganze Stamm derer von der Weiden.

Die programmatische Fixierung Stifters auf das autonom gesetzte Wesen der "Dinge" ist bekannt. ${ }^{44}$ Eine Sprache, die ihm dienen will, muß sich des ästhetischen Scheins enthalten. In Stifters letzter Erzählung kulminiert die Bemühung um Scheinlosigkeit, indem sie ins Gegenteil umschlägt. Denn anstatt daß die Wirklichkeit gleichsam aus dem Mangelzustand ästhetischer Illusion heraustritt, nähert sich die Einebnung der Fiktion einem Zustande der Sprache, wo diese als reine Selbstreferenz, als Schleier ohne Verborgenes zurückbleibt. Die semantischen Zeichen stellen keine Interferenzen zwischen Sprache und Nichtsprachlichem her. Nach der textabgewandten Seite hin sind sie stumm. Sie evozieren nichts Fernes, sind nicht auratischer oder magischer Natur. Sie haben - ebenso wie die von den Protagonisten zelebrierten Rituale - den kultischen Ursprung des symbolischen Aktes, Versichtbarung des Unsichtbaren und individueller Platzhalter des Allgemeinen zu sein, abgestreift und sich in fungible Bestandteile eines Systems semantischer Ökonomie verwandelt. Der Text hat die Schwelle von der Kulthandlung zum reinen Spiel überschritten; die eingesetzten Zeichen enthalten kein Element von Úberschreitung mehr, ihre Affinität auf das Vorsprachliche oder Außersprachliche wird gezielt unterbunden. Damit hängt logisch zusammen, daß die Welt des Frommen Spruches eine reine Kunstwelt ist, auf Zeremonien und sprachlichen Konventionen aufgebaut. Nicht einmal der Fernblick enthält eine Suggestion von Ferne. Das Panorama erscheint nur als das ausgedehnteste einer Folge von Interieurs.

4 Vgl. u.a. Wilhelm Dehns anregende Untersuchung: Ding und Vernunft: Zur Interpretation von Stifters Dichtung (1969). Der Fromme Spruch wird nur als eine "Geschichte vom Mißverstehen der Dinge mit dem Tone des Humors" erwähnt, die "auf geheimnisvollen Wegen doch zu ihrem Ziel kommen" (S. 53). 
Zu ihren Füßen war die Blöße, dann strich der Blick über die Wipfel des Waldes dahin, dann traf er Gebäude mit Feldern, Wiesen, Wäldchen, Obstbeständen, zerstreuten Meierhöfen, Ortschaften, Kirchtürmen und Schlössern, und endete mit dem Gürtel des blauen Gebirgszuges, der den glänzenden Himmel schnitt. (700f.)

Ein einziger Satz durchmißt den Raum von den Füßen der Betrachterin bis zum Himmel, der, traditionellerweise Bild des Ubergangs vom Sichtbaren zum Unendlichen, hinter dem Gewaltakt des Schnittes verschwindet. Kaum je ist ein Panorama mit weniger magischer Kraft beschrieben worden.45 Hier wird keine angeschaute Welt ins Wort gebannt. Ebensowenig ist das Verhältnis von Sprache und Wirklichkeit von der Art, daß erstere letztere vor das Auge des Lesers riefe. Was einmal Gegenstand liebevoller Erzählkunst war, ist zu nominaler Aufzählung zusammengeschrumpft, zur Kette von syntaktischen Leerstellen, in die sich beliebige Benennungen einsetzen lassen. Weniger kann nicht gesagt werden. Doch produziert Stifters "irreduzibles Sprechen" ${ }^{* 6}$ keine kohärenten Realitätsbilder mehr. Wird der innere Zusammenhalt der Dinge durch rigorosen Nominalstil und das Verfahren der Dequalifikation auf die Ebene der Grammatik überwiesen, so versagt diese prompt, indem sie modal unterschiedslos Felder, Ortschaften und Schlösser den Gebäuden unterordnet. ${ }^{47}$ Während Stifter die Naturschilderungen auf ein topographisches Protokoll zu reduzieren scheint, so ist doch die Landkarte, die er zeichnet, nicht rekonstruierbar. Gerlint geht im Kreis, aber es wird nicht klar, in welche Richtung sie aufbricht, noch wie sich Hinweg und Rückweg zueinander verhalten. Wenn die Anschaulichkeit der Darstellung ihrer höheren Präzision hätte geopfert werden sollen, so ist diese Absicht mißlungen. Die nahtlosen Positionsbestimmungen verzeichnen ein La-

${ }^{45}$ Der Paradetext für die Entauratisierung des Panoramas ist die Einleitung zur Erzählung Der Waldgänger. Dort ist die Arbeit der Austreibung des Romantischen noch thematisch festgehalten.

Wie unbestimmt der zitierte Panoramablick bleibt, kann wiederum der Vergleich mit den Wablverwandtschaften erläutern, wo im Eingangstableau Blickender und Erblicktes in festgefügte Relationen gesetzt werden: "Man hat einen vortrefflichen Anblick: unten das Dorf, ein wenig rechter Hand die Kirche, über deren Turmspitze man fast hinwegsieht; gegenüber das Schloß und die Gärten.... Dann ... öffnet sich rechts das Tal und man sieht über die reichen Baumwiesen in eine heitere Ferne." (Gedenkausgabe [2. Aufl. 1962], IX, 9). Horst A. Glaser gebührt das Verdienst, den Realismus der Stifterschen Landschaften bezweifelt und dagegen behauptet zu haben, daß "die Gegenstände der Landschaft bei der Beschreibung mit ihrem Namen konvergieren" (Die Restauration des Schönen: Stifters 'Nachsommer' [1965], S. 13).

${ }^{46}$ Diesen treffenden Ausdruck verdanken wir Heribert Kuhn. Von ihm stammt auch der in seiner Undurchführbarkeit bezeichnende Vorschlag, solche Szenarios zu zeichnen.

${ }^{47}$ Grammatikalisch trifft Gerlints Blick auf "Gebäude mit... zerstreuten Meierhöfen, Ortschaften, Kirchtürmen und Schlössern." Stifters schriftstellerische Logik der Befestigung hebt die Anschaulichkeit seines Schreibens vollends auf. 
byrinth. Wie beharrlich auch die Sprache auf die Objektivität verweist, die sie sich zugrundegelegt haben will, so ist doch das Objektive logisch nicht mehr lebensfähig. Die beanspruchte Referentialität der Sprache greift nicht. Ohne es jemals auszusprechen, deutet Stifters Text stets auf sich selbst als Text zurück. Auf eine eigentümliche Weise ist allen Wörtern die Mitteilung aufgegeben, daß sie nichts als Wörter sind. Statt "wirkliche Wirklichkeit" für sich reklamieren zu können, machen sie sich unausgesetzt auf ihren Sprachcharakter hin transparent. Sie formieren einen hortus conclusus der Zeichen. Der alte Stifter war sich bewußt, daß seinen Texten ihre Konstruiertheit vorgehalten werden könnte. Seinen Bericht Aus dem bairischen Walde beginnt er mit der Bemerkung, "daß, wenn die Sache eine Dichtung wäre, man ihr den Vorwurf der Absichtlichkeit machen würde." ${ }^{48}$ Der etwa gleichzeitig entstandene Fromme Spruch stellt solche "Absichtlichkeit" weitaus deutlicher heraus. Durch die Hypertrophie des Künstlichen durchbricht Stifter einen Illusionismus, der dem Leser gestattet, den hinter dem Werk stehenden Handwerksprozeß zu vergessen.

VI.

Wenn der Gestaltungsprozeß des Textes bisher vorwiegend in den Kategorien einer Logik der Reduzierung beschrieben wurde, so hieße es doch die Erzählweise des alten Stifter gründlich verfehlen, wollte man sie eindimensional in diese Bahn der Negation einlegen. Es kann weniger von Verfall als von zielstrebigem Abbau gesprochen werden. Stifters Technik der Reduzierung ist das Ergebnis seines ästhetischen Rigorismus, nicht eines sentimentalen Dilemmas. Entsprechend ist es sein Bestreben, die Reduzierungen selbst unkenntlich $\mathrm{zu}$ machen. Er genießt förmlich den Aufbau einer Ordnung ohne Widerstände, soweit dieser gelingt; das mag den Grundton der Altersheiterkeit erklären. Aspetsberger hat die zutreffende Beobachtung gemacht, daß der alte Stifter dort weiterschreibt, wo der Nachsommer glücklich endet und rechtens jedes Erzählen, das dem konfliktuellen Schema und der epischen Progression verpflichtet ist, aufhören müßte. Von dem "Götterreich" des durch seine Hochzeit zu "gottgleicher Identität” gelangten Heinrich Drendorf

selber ist nichts mehr zu sagen, da sich im erreichten Ganzen alles gleichbleibt, die Sprache nicht mehr der Uberwindung von Differenzen, sondern nur mehr der Bestätigung von Identitäten dient - freilich kann auch dort die Sprachmaschine aufgestellt und gedreht werden - aber ihre dann identen (tautologischen) Sätze und gemeinten Substanzen, schon im Nachsommer ausreichend beobachtbar, werden erst in manchen späten Erzählungen thematisch, dann aber in ironischer, manchmal vielleicht auch selbstironischer Brechung,

48 MSB, 569. 


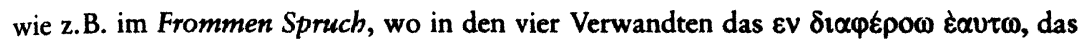
Eine in sich selbst Unterschiedne, in der Familiensubstanz gesichert und in der Verwandtenehe bestätigt, in Rede steht... (Gelinge die Idylle nicht, so meinte schon Schiller, so sei die Komödie weiterhin die höchste Form der Dichtung. $)^{49}$

Was den Anschein von Komik erwirkt, ist eben die Tatsache, daß Widerstand und Dissens, die Lebensbedingungen von Sprache, weitestgehend ausgelöscht sind und dennoch ein Text existiert und sich ausbreitet. Die Elimination des Zufälligen, der Streubreite von Erscheinungen, Beziehungen und Handlungen, die Ausdünnung des epischen Volumens greifen auf den substanziellen Zeitträger selbst, die erzählerische Spannung, über. So entstehen die langen Passagen, deren Sinn es allein ist, den ordentlichen und ereignislosen Gang der Dinge zu notieren. Der Text entwickelt eine Sprache, die Mimesis der verstreichenden Zeit sein will, ohne doch die Zeit als Leere, als Vakuum in Erscheinung treten lassen zu dürfen, ohne eine Lücke zu dulden für das Nichts, das die dargestellte Welt des Müßigganges überschwemmen könnte. Dauer wird vorgeführt als notwendiges Prädikat richtigen Lebens. Und so vergehen im Frommen Spruch mehr als vier Jahre, bis endlich geschieht, was geschehen mußte, und was man auch in einigen Wochen hätte erledigen können. ${ }^{50}$ Stifters Zeit ist die Zeit derer, die (auf nichts) warten. Weil alles gleich gilt, kein Augenblick mehr oder weniger zählt als ein anderer, weil aber Spannung auf Fokussierung ebenso wie Auslassung beruht, darf keine Spannung éntstehen. So kommen Sätze zustande, die nur noch durch Einbau einer syntaktischen Unrichtigkeit die Illusion epischen Flusses erzeugen wollen und damit in mikroskopischer Verkleinerung noch einmal zu erkennen geben, daß Kohärenz aus der Uberwindung von Zäsuren entsteht: "Dann begann das Mahl, und hatte seinen Fortgang" (702). - Es ist schon gesagt worden, daß die Bauart des Gesamttextes sich in dem Zeremoniell der Gespräche spiegelt. Durch die prästabilierte Konkordanz des Gesagten werden alle Verständigungen im Grunde rhetorisch; wie überhaupt ein Sprechen rhetorisch ist, das nicht aus Dissens hervorgeht. Solches rhetorische Sprechen hat die Tendenz, sich in Nichtigkeit zu verflüchtigen. Stifters Thema aber ist gerade die rhetorische Ordnung, die Differenzlosigkeit, die zum Verstummen neigt und der er dennoch Extension, ja Totalität verleihen will. So ergibt sich mit Notwendigkeit und keineswegs aus übertriebener Stilisierung die Kunstform

49 Aspetsberger (1983) (Anm. 32), S. 203.

${ }^{50}$ In der Nachfolge G. Wilhelms (Anm. 1) fällt die Sekundärliteratur der Zeitdehnung in Stifters Erzählung zum Opfer und behauptet, die Handlung dauere nur drei Jahre, indem sie vergißt, daß zwischen den Rosenblüten (712 und 714) wiederum ein Jahr vergeht. Solchen Fehlleistungen setzt Naumann (1979) (Anm. 31), S. 69 die Krone auf, indem sie das "fünf Uhr nachmittags" des zweiten Satzes (665) in den "Morgen des 24. April" umdeutet. 
der ins Sprechen gebannten Identität: das Ritual. Die Sätze werden nicht weggekürzt (weil sie keinen Spannungsausgleich erzeugen und daher unnötig sind), sondern in identischen Wiederholungen verdoppelt. Das Ritual ist die Form der Zeitsistierung in zeitlicher Darstellung. Um es in dieser Funktion zu bestärken, erhebt es Stifter zur breit mit aller Pracht und Feierlichkeit ausgestatteten Zeremonie, zur Zelebration der Jahrestage und Feste ebenso wie des Alltags, und eine der auffälligsten Redekonventionen der Figuren, das Fehlen jeder Neugierde und Nachfrage, betont die sakrale Scheu, die nicht nur vor den Worten, sondern auch vor der Weihe des Schweigens, die sie mittransportieren, gefordert ist. Stifter läßt den Erzähler sich in den Habitus eines mittelalterlichen Chronisten einpassen, das heißt erzähltechnisch in der Ordnung des Textes verschwinden. Die Stagnation, die der Text durchexerziert, will gefeiert, genossen, ja geheiligt, nicht erlitten sein.

Dem Spiel des Zeremonials ordnen sich alle in den Text aufgenommenen Inhalte und Tätigkeiten unter. Sie gewinnen dadurch die Würde des Regelmäßigen. Der Reiz der Zeremonie ist nicht der einer Ausdrucksform von Individualität. Wenn dem Konzept der Individualität im neunzehnten Jahrhundert die Forderung nach Entsagung historisch beigestellt ist, so hat das Spiel der Gleichheiten den Sinn, die Arbeit des Verzichts in einen perpetuierlichen Akt der Erfüllung zu verwandeln. Indem es alles Individuelle unsichtbar macht, können auch Versagungsleistungen nicht mehr namhaft werden. Die Angst vor dem Neuen, die sich in ihm verbirgt, wird niemals thematisch; die Maschinerie des Zeremoniells saugt alle Abweichungen ab, die sie aus der Latenz hervortreten lassen könnten. Zweifellos läßt sich dieses Verfahren der theoretischen Apparatur der Psychoanalyse unterwerfen und dem Begriff der Zwangshandlung zuordnen, die Freud aus unbewußten Schuldgefühlen ableitet: "Das Zeremoniell beginnt ... als Abwehr- oder Versicherungshandlung, Schutzmaßregel."

Die Zeremoniell- und Zwangshandlungen entstehen ... teils zur Abwehr der Versuchung, teils zum Schutze gegen das erwartete Unheil. Gegen die Versuchung scheinen die Schutzhandlungen bald nicht mehr auszureichen; es treten dann die Verbote auf, welche die Situation der Versuchung ferne legen sollen.... Andererseits stellt das Zeremoniell die Summe der Bedingungen dar, unter denen anderes, noch nicht absolut Verbotenes erlaubt ist. ${ }^{51}$

Hierfür nennt Freud Sexualgenuß und Ehezeremoniell als Beispiele. In Anbetracht von Stifters Frommem Spruch können solche Analysen nur redundant erscheinen. Die strengen Parallelismen des Textes paralysieren die zwischen den Personen wirksamen libidinösen Wunschenergien, indem sie sie auf einem Ni-

${ }^{51}$ Freud, Gesammelte Werke, Londoner Ausgabe, VII, $135 \mathrm{ff}$. 
veau gleichbleibender Temperierung halten. Der Ausruf "Ach, welch gräßliche lange Weile"s2 aus den Wiener Salons wird zur Umschreibung des einzig möglichen Umgangsstils, der einzig möglichen Existenzform.

Die unablässigen Rituale des Einverständnisses, der Konformität, der wohltemperierten Zuneigung machen Autorität unsichtbar, indem sie zwangloses Dasein und unbedingte Unterwerfung koinzidieren lassen. Von der scheinbaren Autonomie der Jüngeren wird die unbedingte Autorität der Alten nicht berührt. Konflikte treten deshalb nicht auf, weil diese Autonomie keinen Inhalt mehr hat, weil stets Einklang herrscht oder, wo er zu fehlen scheint (Liebe der Jungen, Irrtum der Alten), das Schweigen die Beziehungen reguliert. ${ }^{33}$ Soweit sie sichtbar werden, haben alle Personen der Erzählung den Prozeß des Sich-Einfügens hinter sich. Damit tritt das pädagogische Moment, das in Stifters Gedankenwelt eine zentrale Stelle einnimmt, in den Hintergrund. Die Erzählung holt ihre Figuren auf einem Niveau ab, auf dem die Arbeit der Pädagogik schon geleistet ist; Dietwin kehrt vom Militär, Gerlint von der Erziehungsanstalt zurück. Beide dokumentieren durch Geschenke, Auftreten, Redeweise und Lebensstil die Sänftigung ihres Wesens. Entsprechend wird ihnen der Freiraum erwachsener Menschen zugesprochen. Die Alten ihrerseits dokumentieren ihre Reife dadurch, daß

${ }_{52}$ MSB, 452. Es ist bekannt, daß Stifter für die Schilderung gesellschaftlicher Rituale auf seine Wiener Salonszenen zurückgreifen konnte, in denen er dem Adel "eine Art Ceremonie, die sie abtun, eine Höflichkeit,... ein Herkömmliches, das geschieht, weil es sonst geschieht" unterstellt, nicht ohne an dem Kritisierten verschwiegenen Anteil zu nehmen: "Das Benehmen aller dieser Menschen war gelassen und harmonisierend, war frei und präzis - aber je länger man es sah, desto bedrückender wurde es einem; denn es war bei allen gleich... - keiner galt, sondern es galten nur alle - darum waren auch alle bei einem" (MSB, 452).

Die implizite Steuerung der Gespräche im Frommen Spruch durch Redetabus ist aber von den taktischen Manövern einer aristokratisch-höfischen Konversationskunst wohl zu unterscheiden. Auf deren Basis können Verwechslungskomödien in der Art von Kotzebues erwähntem Einakter sich abspulen. Dort entsteht die Verwicklung durch eine Kluft zwischen dem, was zu sagen schicklich ist, und dem, was die Protagonisten wissen. Stifter dagegen steht mit Entschiedenheit in der Tradition eines bürgerlichen Aufrichtigkeitszwanges, wie ihn Immermann in den Epigonen beispielhaft formuliert hat: "Nein, bei uns müssen wir beginnen, und mit unsrem Selbst den ersten Baustein zum Tempel der neuen Andacht tragen. Lege den Gehalt einer Gesinnung auch in das kleinste Tun! Sprich nichts, als was du wirklich gedacht hast! Sei wahr in jedem Atemzuge! Nach diesen drei Vorschriften lassen Sie uns jeden Moment unsres Daseins prüfen, dann haben wir die Befugnis, unerbittlich gegen andere zu sein. (Karl Immermann, Werke in fünf Bänden, hrsg. Benno v. Wiese [1971], II, 122.)

${ }^{53}$ Gerlint kann sich nach eigenem Wunsch einrichten, aber versäumt es nicht, die Billigung der Tante einzuholen (708). Sie wird von Augustes Einladung erst nachträglich verständigt, aber ist selbstverständlich der gütigen Tante dankbar (703). Sie wird zu Dietwins Heiratsantrag gehört, aber ihr Votum wird lediglich "in Betracht" gezogen (734). 
sie sich der Vergeblichkeit aller Weltverbesserung bewußt geworden sind..$^{54}$ Das pädagogisch zu erreichende Ziel hatte nicht bloß in der Verfeinerung der Sitten oder äußerlichen Bändigung der Impulse bestanden. Stifters Pädagogik ist ein Schweigetraining. Er artikuliert sie unter dem Eindruck der Revolution. Schon in Ausführungen zum Schulunterricht von 1849 fordert er dazu auf, den Kindern die Erinnerung an die Revolutionsereignisse dadurch zu entziehen, daß man deren sprachlichen Ausdruck unterbinde. Kindlich-gedankenlose Redensarten, wie sie ihm zu Ohren gekommen seien, "die die Seele schaudern machen könnten, Worte von Morden, Brennen und Gotteslästern” seien für die Kinder verhängnisvoll, denn wenn "einmal Gelegenheit kommt, sind ihnen die Begriffe geläufig und gelangen viel leichter zur Tat." ${ }^{\text {ss }}$ Seine Pädagogik, die sich zur Aufgabe stellt "die bösen Eindrücke, die aus den Uebeln der Zeit hervorgegangen sind, nach und nach zu verwischen und unschädlich zu machen" (ebd., S. 207), ergänzt die Restaurationspolitik darin, dem Geist der Revolte den semantischen Boden abzugraben. Erziehung nach diesem Programm ist Sprachentzug. Sie soll die Ordnung der Welt unhinterfragbar machen. Die Arbeiten der mittleren Periode unterstehen diesem programmatischen Vorsatz. Das wird vielleicht am deutlichsten in der Erzählung Granit, wo ein kleiner Junge schuldlos bestraft wird und der Großvater ihn damit tröstet, daß er ihm von der Pest erzählt, die früher einmal ins Land gekommen sei. Der Trost des Großvaters besteht genau besehen darin, pädagogische Gewalt durch Schicksalsgewalt erzählerisch zu spiegeln; fernab von jeder Geste der Entschuldigung sucht er das erlittene Unrecht nicht etwa zu erklären, indem er es auf einen verborgenen Sinn hin transparent macht, sondern dadurch, daß er es sprachlich verdoppelt. Sinngebend für die Gewalt im kleinen soll das unbegreifliche Dasein der Gewalt im großen sein. Ja die in der Geschichte des Großvaters enthaltene Botschaft formuliert ein geradezu kafkaeskes Paradox. Schuldig werden die Menschen erst, als die Pest über sie hereinbricht, die "Kinder liebten ihre Eltern nicht mehr und die Eltern die Kinder nicht"; $; 6$ soll also die Seuche eine "Heimsuchung" (ebd., S. 39) Gottes sein, so straft sie die Menschen für das Verhalten, das sie annehmen, wenn die Strafe erscheint: die Strafe selbst macht die Schuldigen. Stifters pädagogische Absicht geht dahin, durch Aufzucht von Sprachlosigkeiten Gewalt sowohl undurchschaubar als unkenntlich zu machen. Die letzten Arbeiten setzen an dem Punkt ein, an dem dieser Prozeß vollendet scheint. Die jüngeren Gerlint und Dietwin haben die Schule des Verstummens hinter sich. Daher rührt

54 Der "Tugendbund gefallener Mädchen," den die Tante zu stiften versuchte, und Dietwins Plan, "alle Staatsschulden" zu beseitigen (677), sind vielleicht die einzigen Gegenstände, die der Text im Einvernehmen mit den rückblickenden Protagonisten der Lächerlichkeit explizit ausliefert. Aprent glaubte auch diese Passage unterdrücken zu müssen.

s5 "Noch ein Nachwort über die Schule," SW, XVI, 205-7, 205.

s6 BS, 32. 
auch der stumme und bewußtlose Gang ihrer Liebe. ${ }^{77}$ Daher rührt die Reibungslosigkeit ihrer Einordnung, die Tatsache, daß sich ihnen gegenüber kein pädagogischer Zwang zu manifestieren braucht. Sie erscheinen frei, weil sie einen Begriff von Freiheit nicht haben. Aufbegehren oder Leiden der Einfügung finden nicht statt, weil ihnen Gestik und Vokabular entzogen sind. Gewalt tritt nicht ins Bild aufgrund ihrer sanften Omnipräsenz. Die Grenze zwischen Redekonvention und Unsagbarkeit ist so tief gezogen, daß sie mit der Grenze des Wissens fast ausnahmslos identisch ist. Dietwin kann, ohne zu lügen, Onkel und Tante diejenigen nennen, die er am meisten liebt (684). Auguste ist die engste Vertraute Gerlints, beide haben keine Geheimnisse voreinander, dennoch weiß sie von keiner Liebe (717). Wie die Konventionen, wie die Liebe, wie das Sprechen ist auch das Wissens nichts, was entsteht. Die beiden Alten teilen sich nichts mit, sondern ohne die Zeitform des Entstehens zu durchlaufen, ist bei beiden stets ein symmetrisches Wissen da. Vier Menschen werden vorgeführt, die in allen Modalitäten der Offenherzigkeit miteinander verkehren und dennoch nichts voneinander wissen, kriminalistisch vorgehen müssen, mit Blindheit geschlagen sind.

Wohl gibt es Ränder der Konvention, an denen das Machtgefälle sich zeigt, auf dem sie beruht. In ihren Gesprächen treten die Geschwister zuweilen als Träger der Sprachgewalt auf.

"Sind sie wo immer," sprach die Tante, "sie haben einen hohen Sinn, und eine Wegwerfung ist nicht zu befürchten."

"Sie ist nicht zu befürchten, und würde nicht geduldet," sagte der Oheim. (711)

Als die Geschwister einsehen, sich in der Neigungsrichtung ihrer jungen Verwandten getäuscht zu haben, geht ihre Unterredung:

Der Oheim sprach: "Das ist nun freilich anders, als wir gedacht haben, wir müssen es hinnehmen, daß wir gedacht haben, was wir gedacht haben.... nun ist die größte Sorgfalt anzuwenden, daß niemand erfahre, welche Gedanken wir gehabt haben.”

...

"Das wagt niemand zu denken," sagte die Tante. (730)

An solchen Stellen nimmt die Repression als Mutter der Ordnung noch einmal Gestalt an. Sie gelangt aber nicht mehr zum Einsatz. Die Sprachregelungen kommen ohne sie aus. Sie setzen die Waffe des Schweigens ein. Auch diesbezüglich führt an den Gesprächen der Alten der Text sein eigenes Verfahren vor. Entweder ist nichts zu verhandeln, weil alle Möglichkeiten von Dissens vorweg beseitigt sind; dann performiert die Rede das Ende der Rede. Immer wieder

${ }^{57}$ Es ist bezeichnend, daß Stummheit bei Stifter auch der akustische Modus ist, nach dem sich die Katastrophen ereignen. Vgl. Mattenklott (1973) (Anm. 18), S. 44f. Walter Benjamin hat das "Zurschaustellen von Gefühlen und Gedanken im tauben Raum" als das "Dämonische" in Stifters Erzählweise ausgemacht. "Dieser unheimliche Zug wird sich bei scharfem Zusehen überall da finden, wo er in einem spezifischen Sinne 'interessant' wird" (Brief an E. Schoen, 17.6.1918, in Briefe, Bd. I [1978], S. 195ff.). 
kommt auf diese Weise die Erzählung förmlich zum Stehen. Wo aber einmal ein Dissens sich aufgetan hat, wie in der Täuschung der Alten, muß das Verschweigen als Strategie eingesetzt werden. Dabei funktioniert die Tautologie - "wir müssen es hinnehmen, daß wir gedacht haben, was wir gedacht haben" - wie eine Klappe, die das Geschehene zuschließt, nicht indem sie es ungeschehen, sondern indem sie es bedeutungslos macht. Dort wo gleichsam zuviel Sprache war, in der Gedankenverfehlung der Alten, entsteht die einzige Situation im Text, wo das Schweigen die Form eines taktischen Manövers annimmt. In der beschränkten Sphäre menschlicher Konventionen tritt die Arbeit der Erzeugung anathematischer Strukturen zuweilen offen ans Licht. Mit allen wohlgesetzten Reden wird eine Zone des Sprachtabus zugleich vorausgesetzt und eingerichtet. "Oheim, wünschet mich nicht fort, lasset mich leben wie ich lebe, hin und hin, ich denke dieser Dinge nicht, du hast nie von ihnen geredet, rede auch nicht mehr von ihnen" antwortet Gerlint auf die Frage nach ihren Heiratsplänen. ${ }^{58}$ Das zwischen den Personen aufgebaute Unvermögen zu sprechen wie zu denken wird aber nicht in irgendeiner höheren Instanz korrigiert. Zwar hält die Erzählung an einem Ort jenseits der Konventionen fest; der "fromme Spruch" markiert ihn. Aber der Himmel, der die Konventionen verdoppelt, weil er die Ehe schließt, die sich aus der sozialen Ökonomie der Personen ohnehin notwendig ergibt, ist seinerseits eine Sphäre sprachloser Macht. Auguste beispielsweise hat die Seufzer von Verehrern nicht verstanden, die ihr galten. Die Tante sagt: "Ehen werden in dem Himmel geschlossen ..., und wenn es der Himmel fügt, wirst du die Seufzer schon verstehen" (704). Die Ordnungen der Sozietät und des Schicksals haben gemeinsam, daß sie durch Unverständnis und Ahnungslosigkeit der menschlichen Subjekte hindurch funktionieren. Konvention und $\mathrm{Fa}$ talität sind Verbündete. Sie greifen ineinander. Was die Konventionen sprachlich nicht regulieren können, geben sie an das Schicksal weiter, das jenseits ihrer nach gleichen Gesetzen waltet. Wenn der ständige Verweis auf die Eigengesetzlichkeit des "frommen Spruchs" überhaupt noch Sinn geben soll, so wäre dieser Sinn darin zu suchen, eine stumme Autorität jenseits aller ihrer Verkörperungen zu verankern. Die Zwänge, die durch Produktion von Unbewußtheit regieren, sollen ungreifbar und subjektlos sein.

VII.

Alles, was geschehen kann, geschieht zu Recht nach dem Gesetz der Fatalität. "So wie mich Gott der Herr bisher noch nie mit einer Krankheit heimgesucht

\footnotetext{
58 Dieses sprachliche Tabu formuliert der jüngere Dietwin in der Parallelsituation auf äquivoke Weise: "Ich bitte dich, Tante, rede nicht davon." Die Tante willigt in die Fixation der Redeweisen ebenso ein wie ihr Bruder: "Nun, ich rede nicht davon" (721f).
} 
hat" sagt die Tante, "so bin ich auch seit unserem letzten Zusammensein gesund geblieben. Ich habe mein einfaches Leben zur Erhaltung meines Körperwohles fortgesetzt, und nehme eine Krankheit, wenn sie Gott sendet, demütig an, und trage, was sie bringt" (666). Kein Widerspruch darf auftreten zwischen der Wertschätzung der Gesundheit, die ohnehin ist, den Anstrengungen, sie zu bewahren, und der Tatsache, daß sie zu verlieren ebenso gut und in der Ordnung wäre. Man lebt, um inhaltslos zu überleben; das Leben selbst verliert seine Wertigkeit. Stifter vollzieht wie seine Sprecherin eine Art nominalistischer Operation, indem er alles zum Rechten erklärt, was sich zuträgt, dadurch aber den Begriff des Rechten zusehends entleert und endlich wegkürzbar macht. ${ }^{59}$ Man kann Stifter einen Tautologiker nennen. Auf drei übereinanderliegenden $\mathrm{Ni}$ veaus arbeitet er an der Annihilation von Bedeutungen durch tautologische Prozeduren. Auf der elementarsten Stufe, vor allem in den deskriptiven Textpassagen, bringt er die Referentialität der Wörter gegen Null, bis sie statt ursprünglicher Lebensfülle bloß noch eine Schemenwelt und zuletzt allein ihre eigene Existenz, ihren Materialcharakter als Wörter demonstrieren. In einer zweiten Ableitung arbeitet die Tautologie nach dem Muster des zitierten Satzes "wir müssen es hinnehmen, daß wir gedacht haben, was wir gedacht haben" als affirmative Verschlußklappe, als eine zirkelschlußförmige Legitimationsstrategie der Ordnung der Sprachkonventionen. Ihre dritte und letzte Funktionsform greift auf den Weltaufbau als ganzen aus. Indem sie die Synonymie noch der härtesten Gegensätze behauptet, insistiert sie mit der Gewalt eines intransigenten Nichtssagens auf dem Bewußtsein, daß alle Antinomien nur aus einer rhetorischen Zerlegung des identischen Guten hervorgehen. Wenn aber alles in der Ordnung ist, bedeutet der Begriff Ordnung nichts mehr. "Es geht so gut, wie alles nur immer gehen kann" (666), "und es sei, wie es will" (692) - solcherart sind die Sätze, die unvermerkt der Totalität eine positive Bestimmtheit verleihen wollen, die sie ihrem Begriff nach ausschließt. Ähnlich ergeht es allen positiven Kategorien im Text. Da alles Tun freiwillig geschieht, kann von Freiheit kaum

${ }^{59}$ Vgl. hierzu Piechotta (1983) (Anm. 3), S. 107: "Das, zeichentheoretisch formuliert, metasignifikante Signifikat 'absolute Ordnung,' mythische Allheit, löst sich, zu Ende gedacht, selbst auf und etabliert - insofern überhaupt noch geschrieben wird - ein Universum tendenziell bedeutungsloser, sinnlos kommunizierender Signifikanten." Piechottas vom Gesamtgedanken ausgehende Deutung trifft sich hier mit dem Ergebnis unserer Detailanalyse.

Die Denkformen der Affirmation geraten in dieser Epoche samt und sonders unter den Druck des Nominalismus. Es ist bezeichnend, wie man diesem Druck gegenüber sogar die Logik des ontologischen Gottesbeweises wiederzubeleben sucht: "Es ist eine unmittelbare Gewißheit," notiert Hermann Lotze, "daß das Größte, das Schönste und Wertvollste nicht bloßer Gedanke, sondern Wirklichkeit sein muß, weil es unerträglich an sich würde, von dem Ideal zu glauben, daß es eine Vorstellung sei, die das Denken wohl in seiner Arbeit erzeugt, die aber in der Wirklichkeit kein Dasein, keine Macht und keine Gültigkeit habe." (zit. n. Martini [1974] [Anm. 6], S. 43). 
noch gesprochen werden, da es keinen echten Dissens gibt, gibt es eigentlich auch keine Identifikation, eine Harmonie ist leer, wenn sie nicht, nach dem idealistischen Dreisatz, durch Aufhebung von Dissonanzen entsteht, jeder im Text spricht seine Liebe zu jedem aus, so daß Liebe als spezifisches Gefühl sich nicht mehr profilieren kann, ${ }^{60}$ und endlich könnte eine Ubiquität von Sinn, die alles Ermessen übersteigt, auch ebensogut Sinnlosigkeit heißen. So entsteht ein Gleichklang der Antithesen, in dem die Sprache, indem sie alles bezeichnet, nichts mehr zu bezeichnen hat. Vom Boden der Sprache aus lassen sich nur analytische Urteile über die Ordnung fällen. Die Sprache ist mit dem Richtigen kongruent. Das Falsche ist Gegenstand des Schweigens. Das Richtige, das Gute, das Edle, die Idealität sind mit den Mitteln dieser Sprache weder zu gewinnen noch zu begründen. Sprache bei Stifter ist nicht das Organ einer Interferenz zwischen dem Ungeordneten, dem Ursprung, der Natur und auf der anderen Seite der Ordnung. Die Ordnung entsteht nicht und bildet sich nicht heraus; sie hat kein Gegenteil, aus dessen Bezwingung sie sich gewönne. Sie hat Neigung zur Tautologie, weil sie ihren Ursprung annihiliert hat. Das Dasein selbst erscheint als die letzte Instanz der Gewalt. Die Sprache, wie Stifter sie vorführt, hat den Auftrag verloren, den die Aufklärung ihr zugedacht hatte: Instrument der Kritik und der Legitimation von Gewalt zu sein. Sie hört auf, ein Wesen zu sein, das der Gewalt gegenübersteht, und wird Organon dieser Gewalt, ihre Daseinsform, ihr grammatikalischer Ausdruck. Und zwar an der Stelle, an der die Gewalt die Metamorphose von den Spielarten ihrer physischen Erscheinung, Stoff, Gestalt, Thema, Person, Bild, Handlung, zu einem unsinnlich und strukturell gewordenen Zwangssystem durchlaufen hat. Wie immer sie dabei im Dienst der reinsten Machtaffirmation steht, so unterläuft es ihr unwillentlich doch, zugleich den schärfsten Eindruck von der realen Unverständlichkeit und Undeutbarkeit des Faktischen zu vermitteln. Für die Sprechenden funktioniert diese Sprache als ein Regulativ von Denkzwang und Denkverbot. Weil ihr Zeremoniell keinen Sinn, kein Telos, wohl aber einen Verlauf hat, der in der ausschließlichen Befolgung der Regel gründet, muß sich die darin wirksame Gewalt begrifflich nicht ausweisen; es funktioniert schleichend und sanft und paralytisch wie alles im Stifterschen Text. Es hat das Vermögen von Erfahrung

${ }^{60}$ Liebe, die wirklich vorkommt, geht unter in dem indifferenten Rauschen der dauernden Behauptung liebender Harmonie. Bei der Initiation Gerlints in den Sozialraum der auf Heirat programmierten Vetternfamilie versichert jeder jedem nichts als Liebe (694ff.). Behauptet der Oheim, daß er sein "liebes schönes Beselein," sein "liebes, gutes Kind" "wahrhaftig ungemein liebt," so begrüßen sich die später Liebenden gegenseitig betont als "sehr liebe Base" und "sehr lieber Vetter." Fazit: "Alle lieben dich," sagt irgendeiner der Dietwins. Die unterschiedslose Versprachlichung des Verschiedenen macht die Liebe zum Wort, das Tauschäquivalent gegen nichts und alles ist. Nur folgerichtig fungiert die Liebe bei dem fast ekstatisch zusammengerafften Ausbruch der Gefühle in der Verlobungsszene nicht als Begründung der Verbindung. In dem Moment, wo wirklich etwas mitzuteilen wäre, muß für den Informationsfluß die wechselseitige Namensnennung ausreichen (727). 
und Selbstbewußtsein gebannt und die Leidenschaft, die doch Ferment der Handlung ist, so weit exterritorialisiert, daß sich die Figuren im Hinblick auf etwas bewegen, das außerhalb ihrer sprachlichen Reichweite und außerhalb des Textes liegt. ${ }^{61} \mathrm{Ihr}$ Sprachvermögen reicht nicht mehr hin, sie in ein subjektives Verhältnis zur Ordnung zu stellen. Die Sprache steht den Sprechenden nur zu Diensten, insofern sie sich fraglos innerhalb der Ordnung aufhalten. Die einzige Aneignungsform, die sie erlaubt, ist die Benennung. Nicht umsonst zerbricht die Grammatik an der Stelle, wo einmal das freie Spiel der Bedeutungen eine subjektive Verfehlung produziert (vgl. 719). Folgerichtig eröffnet sie auch keinen Raum der Moralität, in dem Gut und Böse als Möglichkeiten von Freiheit sich begegneten. Das Böse kommt nicht vor. Existiert es, so ist es jedenfalls stumm. Stifter ist deshalb kein moralischer Autor. Es kann den Weg zum Richtigen, die moralische Leistung, das Niederringen des Bösen nicht darstellen. Personen, die das Fatum regiert - Abdias, Ditta, der Rentherr aus Turmalin - sind keiner Rettung fähig, ebensowenig wie es eine Entrinnbarkeit aus dem Rechten gäbe.

Wo aber in den Kategorien von Moralität nicht mehr gedacht werden kann, hebt Stifters Begriff der Pädagogik sich endgültig auf. Wenn die Grenzen des Rechts und der Sprache identisch sind, kann Stifter mit den zu Bildenden nur dort kommunizieren, wo sie noch nicht sind und wohin sie - man weiß nicht wie - erst gelangen sollen. ${ }^{62}$ Wenn das Legitimationsdenken vom Subjekt aus ins Leere greift, bleibt als Mechanismus der Pädagogik nur die Subjektminimierung, die tautologische Einschwörung auf die Gesetzlichkeit der Welt übrig. Bürgerliches Ordnungsdenken ist bei dem Realisten Stifter in ein Stadium getreten, in dem der Wille, die Ordnung wirklich zur Rede zu stellen, ihrem mentalen Totalverlust gleichkäme. Hält die Ordnung das Sprachmonopol inne, so ist jede Abweichung mit Aphasie geschlagen. Begreifen hieße überschreiten. Die Menschenbildung muß das Unglück des sprachlichen Absturzes aus der Ordnung zu verhindern wissen. Auch hierin steht Stifter auf der Höhe der Philantropie seiner Zeit. Sein Leipziger Kollege Daniel G.M. Schreber warnt eindringlich vor der Gefahr des Weltverlusts durch Phantasie:

61 "Nichts ist thörichter, als zu glauben, die Kunst stelle Leidenschaften dar" (Albumblatt Stifters vom 18.4.1855, zit. n. VASILO, 20 [1971], 77).

62 Dies ist der Grund, warum das Stifter/Aprentsche Lesebuch zur Förderung humaner Bildung (1854; Neuausgabe München 1947) abgelehnt wurde. Stifters Bericht an Heckenast, 2.1.1855: "Unser Lesebuch ist nicht für die Realschule approbiert worden." "Wir meinten, wenn Edles Großes, das in die Herzen der Jugend gesät werden solle, und sie auf einen schöneren und größeren Lebensweg hinstellt, geboten wird, und dies in einer vollkommenen deutschen Sprache, werde die Sache für sich reden, daß man mit Freude darnach greifen werde, und daß man einsehen werde, daß alle untergeordneten Rücksichten ... ohnehin in dem höheren Zwecke liegen; allein man fordert die niederen Zwecke in einem ausgedehnten Maße, weil man den höhern nicht zu sehen vermochte." "Daß mich die Sache sehr angegriffen hat, können Sie sich denken."

Vgl. Enzinger (Anm. 9), "Adalbert Stifters 'Lesebuch," 267-94; sowie Sepp Domandl, Adalbert Stifters Lesebuch und die geistigen Strömungen der Jabrhundertmitte (1976). 
Als ein Zeugnis für die Unvollkommenheit pädopsychologischer Kenntnisse ist es zu betrachten, daß die Ansicht, Fabeln und Mährchen seien gerade für das zarte Kindesalter eine passende Geistesspeise, noch bis auf den heutigen Tag sich erhalten ... konnte.... Das Kind hat in den ersten Jahren des erwachten Selbstbewußtsein noch genug zu thun mit Erfassung und Zurechtlegung der Wirklichkeit. Es muß erst den Boden der Wirklichkeit sicher unter den Füßen haben und immer leicht wiederfinden können, bevor es kleine Ausflüge in die dichterische Gedankenwelt... ohne Gefahr der Verirrung unternehmen darf. ${ }^{63}$

Wenn Ordnung nicht mehr als Produkt eines rationalen Diskurses gilt, sondern diesen zugleich setzt, begrenzt und suspendiert; wenn andererseits subjektive Spontaneität nicht mehr welthaltig ist, sondern sich nur in Formen der Abirrung artikuliert; wenn das Aufreißen einer Differenz irreparabel wäre, weil es keine denkmögliche UUberbrückung gäbe, - so ist die Einübung in indikativisches Denken ein seelisches Überlebenstraining, das niemals ausgesetzt werden darf. ${ }^{64}$ Dementsprechend denunziert die Poetologie nicht nur Stifters, sondern auch der anderen poetischen Realisten wie Keller und Raabe, die Einbildungskraft, die einmal Organon von Weltschöpfung und ästhetischem Gottesstellvertretertum war, als ein bedrohliches und pathogenes Geistesvermögen. Der Konjunktiv der Phantasie und des Wunsches schlösse den Konjunktiv von Unordnung und Katastrophe in sich ein.

"Ist kein Unfall vorgekommen?" fragte sie.

"Ein zerbrochenes Rad, das wieder gemacht worden ist," entgegnete er, "eine kranke Kuh, die wieder gesund ist, und anderes, dessen ich mich nicht mehr entsinne."

"Das ist ohne Bedeutung," sagte sie, "bei mir ist gar nichts vorgekommen."

"So stehen die Sachen vortrefflich," antwortete er. (666)

Vortrefflich ist die Bedeutungslosigkeit der Ereignisse. Vortrefflich ist es, wenn nichts geschieht. Darin ist implizit mitgedacht, daß jedes Ereignis nur eine potentielle Störung der Regelwelt bedeuten kann. Das stets gefährdete Ordnungsdenken sucht sich in Richtung Immobilität zu retten. Die Subjekte müssen sich auf diese Immobilität einschwören lassen. Stifters Gestalten wünschen nichts, leben auf nichts zu, als was nicht ohnehin Gang der Dinge ist und in Erfüllung geht. Und wenn sie je einmal mehr begehrt haben sollten als das, was sie haben, so nur in Form einer familieneigenen Narrheit, die, wie im Frommen Spruch, auf die Zeit der Hohenzollern zurückreicht (676) und fester altehrwürdiger Bestandteil der Normalität ist. Subjektivität, die sich in der Differenz behauptet, würde die starre ratio der Ordnung verfehlen.

${ }^{63}$ Daniel G.M. Schreber, Ein ärztlicher Blick in das Schulwesen in der Absicht: zu heilen, und nicht: $z$ u verletzen (1858), S. 39f. - In diesem Geist nehmen Stifter/Aprent auch so gut wie keine Märchen in das Lesebuch auf: nichts von Tieck, von den Grimms hauptsächlich mittelalterliche Genealogien, von Fouqué nur zwei Gedichte und 'Aussprüche.'

${ }^{64}$ Der Fromme Spruch verwendet dementsprechend das Wort "Einbildungen" als Synonym für Liebesvorstellungen (678). 
VIII.

Unschwer ist zu erkennen, daß das Behagen in der Nichtdifferenz, das Stifters Spätwerk zelebriert, dünn ist, daß eine omnipräsente Angst es umstellt, ja daß die Angst vor Verfehlung selbst den Motor der Sprachmaschine bildet. Alles, was nicht Affirmation, Wiederholung, sprachliche Verdoppelung ist, überschreitet eine Grenze zur unwiderruflichen Abnormität, schließlich zum Wahnsinn. Zwischen der Starre der Welt und dem Wahnsinn ist kein Drittes mehr; sie fixieren sich gegenseitig. Der Sohn des erwähnten Pädagogen Schreber, Daniel Paul Schreber, den die Verfasserschaft der Denkwürdigkeiten eines Nervenkranken zum Paradefall der Psychoanalyse machte, konnte sich zum Zwangssystem seines Vaters nur noch durch Wahnsinn sprachlich in Beziehung setzen.65 Der Begriff des 'Denkzwanges,' den er entwickelt, ist der Sehnsucht Stifters geistesverwandt, sich einer "Enthaltsamkeit von geistiger Tätigkeit" zu befleißigen. ${ }^{66}$

${ }^{65}$ Morton Schatzman deutet D.P. Schrebers Wahnsystem als genaue Ubersetzung des Zwangssystems des Vaters, nach Maßgabe einer "Vorschrift, die ihm verbot, seinen Vater als seinen Verfolger zu identifizieren" (Die Angst vor dem Vater [1974], 107).

${ }^{66}$ Die bemerkenswerte Briefstelle Stifters lautet im Zusammenhang: "Die Ärzte wollen noch immer, daß ich sehr, sehr wenig sitze, und möchten auch, daß ich geistig gar nicht tätig wäre. Das wenige Sitzen kann ich so ferne zuwege bringen, als ich nur täglich eine gewisse Zeit dazu bestimme, in der ich an meiner Schriftstellerei arbeite, und die ich aus Vorsicht nicht zu groß ausmesse, wie ich es aber mit der Enthaltsamkeit von geistiger Tätigkeit machen soll, weiß ich nicht; denn ich habe mir das Denken angewöhnt, und kann es mir jetzt nicht mehr abgewöhnen. Es sucht mich bei körperlicher Arbeit heim, und kömmt im Schlafe in der Schalksnarrheit der Träume. Nur bei Spaziergängen in einer erhabenen Natur wie im bairischen Walde oder auf meinem Kirchschlagberge denke ich weniger, und meine Einbildungskraft wirkt mehr empfangend, da sie die Größe, die sie umgibt, mit einer Art Wonnegefühl aufnimmt. Meine Freunde erhalten auf diese Weise weniger Briefe als sonst, und die am wenigsten, denen ich am längsten schreiben möchte, wozu ich dann nicht komme" (An Freiherrn von der Kriegs-Au, 8.2.1867).

Der Wahnsinnige und der Dichter stehen in geschlossener Phalanx mit dem Wissenschaftler. Gustav Theodor Fechner, der 1860 den Begriff der Psychophysik prägt, beschreibt bereits anderthalb Jahrzehnte zuvor seine scheiternden Bemühungen, durch Denkverzweigung seiner Krankheit vorzubauen: "Ein Hauptsymptom meiner Kopfschwäche bestand nämlich darin, daß der Lauf meiner Gedanken sich meinem Willen entzog. Es schied sich mein Inneres gewissermaßen in zwei Teile, in mein Ich und in die Gedanken. Beide kämpften miteinander; die Gedanken suchten mein Ich zu überwältigen und einen selbstmächtigen, dessen Freiheit und Gesundheit zerstörenden Gang zu nehmen, und mein Ich strengte die ganze Kraft seines Willens an, hinwiederum der Gedanken Herr zu werden, und, sowie ein Gedanke sich festsetzen und fortspinnen wollte, ihn zu verbannen und einen andern entfernt liegenden dafür herbeizuziehen. Meine geistige Beschäftigung bestand also, statt im Denken, in einem beständigen Zügeln von Gedanken" (zit. n. Gerhard Mattenklott, Blindgänger [1986], S. 149). 
So trat die Einwirkung [göttlicher Strahlen] schon verhältnismäßig früh in der Form des Denkzwangs auf.... Das Wesen des Denkzwangs besteht darin, daß der Mensch zu unablässigem Denken genöthigt wird, mit anderen Worten das natürliche Recht des Menschen, seine Verstandesnerven von Zeit zu Zeit durch Nichtsdenken (wie es am ausgeprägtesten im Schlafe geschieht) die erforderliche Ruhe zu gönnen, wurde mir von Anfang an durch die mit mir verkehrenden Strahlen verschränkt, die fortwährend zu wissen begehrten, woran ich denke. ${ }^{67}$

Gegen solche Gefahr, einmal nicht Rechenschaft von sich geben zu können, geht Stifters poetologische und psychoökonomische Assoziationskontrolle an. Gegen die immerfort drohende Revolte der Denkmöglichkeiten, die nur noch katastrophale Möglichkeiten sein können, errichtet er sein Bollwerk des schweigenden Schreibens. Er filibustert, damit keine Partikel des Schreckens, der eintreten würde, wenn die Sprachmaschine zum Stehen käme, in sein Bewußtsein dringen. Dem Sog semantischer Abweichungen kann er sich nur entziehen, indem er sich als "Definitionsmagazin"68 betätigt. In einem totalitären Gestus gegenüber seinem Publikum will Stifter diesem vorschreiben, was es zu denken habe: möglichst gar nichts mehr. Hein, der frühe Biograph, übermittelt die Anekdote, wie unerbittlich hart der Dichter gegen ihm ungenehme Einbildungen, die sich aus seinem Vortrag ergeben hätten, vorzugehen pflegte:

Der Künstler verfuhr aber auch bei seiner Arbeit ganz absolutistisch. Ließ es sich einer der Anwesenden beikommen, ein Seperatbildchen zu formieren, so war Stifter flugs mit dem Vertreibpinsel da und hatte das werdende Ding weggewischt. ${ }^{69}$

Hier soll nicht der Versuch unternommen werden, die Ätiologie des behandelten Komplexes von Aphasie, Angst, Sprachgewalt und literarischer Moderne auf billige Weise biographisch zu entschlüsseln oder dem alten Stifter vorzuhalten, $\mathrm{da}$ er das Ethos seiner Dichtungen nicht am eigenen Leibe vorzuexerzieren vermochte. ${ }^{70}$ Dennoch bezeichnen die Leerstellen und Ausfälle der Stifterschen Rede recht exakt biographische Zwangsvorstellungen, die innertextlich in eine Angst vor Kunst überhaupt transformiert werden. Der Latenz des Wahnsinns

${ }_{77}$ Daniel Paul Schreber, Denkwürdigkeiten eines Nervenkranken (1985; zuerst 1900), S.38.

${ }^{68}$ Brief an Heckenast, 17.3.1866.

${ }^{69}$ Friedrich Simony, zit. n. Hein (Anm. 4), S. 610. Für die Furcht vor der Einbildungskraft läßt sich eine lange, aus der Aufklärung hergeleitete Traditionslinie aufzeigen, die sich auch immer wieder in der Pädagogik geltend macht. Vgl. dazu neuerdings Christian Begemann, Furcht und Angst im Prozeß der Aufklärung (1987).

${ }^{70} \mathrm{Kaum}$ jemand hat so gegen sein eigenes Leben angeschrieben wie Stifter. So läßt er in seinem persönlichen Leben auch sein eigenes Schweigegebot außer Acht. Aprent berichtet: "Kam ein Freund, so war die Krankheit sein erstes und letztes Wort und man machte nur ungern den Versuch, ihn von dem traurigen Gegenstand abzubringen, weil er doch erleichtert schien, wenn er davon sprechen konnte.” Johannes Aprent, Adalbert Stifter: Eine biographische Skizze [1955; zuerst 1869], S. 86). 
war sich Stifter in seinem persönlichen Leben recht wohl bewußt. ${ }^{71}$ Sie schreibt sich bis in die Formenwelt der Buchstaben ein, die er aufzeichnet. "Diese Schrift ist pathologisch" behauptet knapp eine graphologische Analyse der Handschrift. ${ }^{72}$ Besonders intensiv war seine Arbeit an der Handschrift des Frommen Spruches. Er habe

an dieser Erzählung mit mehr Sorgfalt gearbeitet... als an anderen. Meine Handschrift war so voll von Umänderungen, daß sie kaum mehr zu lesen war. Ich ließ sie abschreiben, und wie Sie gesehen haben, machte ich in der Abschrift wieder durchgreifende Änderungen. $^{73}$

Das monomanische Bestreben, einen Text mit monovalenten Sinnbezügen zu schreiben, scheint so labyrinthisch aufwendig gewesen zu sein, daß es zur Unleserlichkeit tendierte und den Dichter vor seinem Elaborat zurückschrecken ließ. Stifters Ringen um Monovalenz steht im Zeichen der Angst vor der unbegrenzten Polyvalenz aller Dinge im Wahnsinn. Solche Angst muß man nicht, was freilich in bezug auf Stifter durchaus möglich ist, als biographische verstehen. Sie eignet sich auch als Signum einer Epoche, in der das bürgerliche Bewußtsein auf der Schwelle steht, die Ungültigkeit der von ihm selbst inaugurierten Sinngebungsverfahren zu entdecken, in der die gesellschaftliche Einrichtung der Welt

${ }^{71}$ So hat Stifter die Umstände seines Todes genau vorhergesehen: “Mit diesem Ubel, das bei mir ohne alle Schmerzen ist..., sind jedoch Seelenzustände verbunden, von denen andere Menschen keine Vorstellung haben: oft tiefe Niedergeschlagenheit, gänzliche Muthlosigkeit, Verzweifeln am Genesen, Unruhe, daß man an keinem Platze bleiben kann, gegenstandslose Angst, Gemüthsschwäche bis zum lauten Weinen, Gereiztheit, ein Sandkorn bringt die größte Aufregung oder plötzlichen Zorn oder ungemeine Betrübniß. Ich habe zu manchen Zeiten zu Gott das heißeste Gebet gethan, er möge mich nicht wahnsinnig werden lassen, oder daß ich mir in Verwirrung das Leben nehme... Ich kämpfte nieder, was ich nieder kämpfen konnte." (Brief an Heckenast, 1.6.1865)

${ }^{72}$ Heinrich Schadner, Die Handschrift Adalbert Stifters (1963), S. 103. Dieser knappe Satz bezieht sich auf einen Brief vom 3.9.1866 an den Bruder Johann. Schadner, der sich auch weitgehend auf philologische Ergebnisse stützt, beschreibt ein für Schrift wie Inhalt zutreffendes, zwischen mikroskopischer Verwirrung und scheinbarer Ordnung im Großen schwankendes Bild: "Die schwankende Größe und Weite der Schrift schaffen mit den unregelmäßigen Zeilenlängen und der äußersten Lageschwankung einen verwirrenden Eindruck. Durch die scheinbar regelmäßige Zeilenführung und den blockartigen Gesamtbau wird allerdings noch ein füllendes und gegliedertes Raumbild vermittelt. Trotz Wahrung der meisten bekannten Formeigenheiten ist eine Formauflösung angebahnt, die sich in der undeutlichen und verwirrenden Schrift kundtut... Mit letzter Kraft möchte hier etwas bewältigt werden, was sich stärker aufdrängt" (S. 104f.).

${ }^{73}$ Aus Stifters Antwortschreiben auf Tepes Ablehnung des Frommen Spruches (31.10.1867). Stifter hat früher mit Heckenast über seine Handschrift korrespondiert (vgl. 17.6.1844; 17.3.1846; 2.10.1848).

Das Herstellen einer ordnenden Abschrift von fremder Hand stellt, soweit wir es überblikken, für Stifter eine Besonderheit dar und mag bei der gedrängten finanziellen Lage verblüffen. Vom Frommen Spruch ist nur diese Abschrift mit Stifters und Aprents Korrekturen erhalten. 
und ihre Legitimierung in die Extreme von stummer Faktizität und geschwätziger Phantasmagorie auseinandertreten. Stifters Sprache, die sich solcher Phantasmagorie nicht ergeben will, produziert tendenziell Nichtigkeiten und ein Geräusch, das in seiner semantischen Indifferenz dem 'white noise,' dem sinnlosen Rauschen der Apparate gleichsetzbar ist. ${ }^{74} \mathrm{Da}$ er aber an der Weltmächtigkeit des dichterischen Sprechens noch dort festhält, wo seine Texte sie längst sabotieren, markiert seinen Abstand zu den expliziten Verabschiedungen der Kunst, wie sie die Avantgardebewegungen des zwanzigsten Jahrhunderts künstlerisch - also in sich widersprüchlich - aufführen werden. Wenn schließlich alle herkömmlichen Funktionen von Poesie ad absurdum geführt sind, erscheint die leere Umrechnung der Wörter in Geld als letzter Restbestand ihrer Funktion. "Denke nur," schreibt der alte Stifter 1866 an seine Frau,

was du mir für ein heidnisches Geld kostest. Wenn ich mit all den Buchstaben, die ich an dich auf das Papier trage, andere Dinge schriebe, und drucken ließe, wie viele hundert Gulden flögen da in das Haus; und dennoch kann ich es nicht lassen, ich gehe alle Male wieder an das Papier, um an dich zu schreiben. ${ }^{75}$

Auch die Liebesbriefe Stifters schreiben vom Schreiben. Real existieren freilich sowohl das Geld als auch die Liebe nur an dem illusionären Ort der Schrift. Denn unter Anrufung des wirklichen finanziellen Ruins breiten die Briefe nur einen beredten Schweigemantel über die längst erloschene oder wohl vielmehr niemals gewesene Leidenschaft zu Amalia. ${ }^{76}$ So sind noch die persönlichen Schriftstücke Zeugnisse einer Ästhetik, in der Ausdehnung und Vielzahl der

${ }^{74}$ Vgl. Friedrich A. Kittler, Aufschreibesysteme, 1800/1900 (1985), der diesen Gedanken vorgeprägt und anhand von literarischen, pädagogischen und psychologischen Texten der Zeit belegt hat. "Sprachstörungen hören auf, alle in den schönen Wortlosigkeiten romantischer Seele zu konvergieren." In einer "langen Liste von Ausfällen wird das Rauschen vor jedem Diskurs Thema und Methode zugleich" (S. 221 und 223).

${ }^{75}$ An Amalia Stifter, 14.6.1866. Aus solchen Uberlegungen heraus entsteht im selben Jahr der von Heckenast abgelehnte Plan, eine Sammlung der eigenen Briefe zu edieren. Wie der Fromme Spruch gelangt dieser Plan einer geglätteten Biographie erst postum zur Ausführung (vgl. an Heckenast 17.3. und 8.4.1866).

Was in ökonomischer Sicht für das Schreiben gilt, gilt erst recht für das Lesen: "Eine derartige Darstellungsweise muß einen Menschen des 19. Jahrhunderts, für den Zeit Geld ist, zur Verzweiflung treiben" notiert Rudolph Gottschall bezüglich des Witiko in den Blättern für literarische Unterhaltung (zit. n. Kurt G. Fischer, Adalbert Stifters Leben und Werk [1962], S. 652).

Zur Rolle des Geldes bei Stifter vgl. auch Aspetsberger (1983) (Anm. 32), 180f. und passim. Freilich ist das Schreiben eine alle Ökonomie sprengende Passion: "Der Teufel hole das Dichterleben, man hat nur Kreuz und Qual dabei, und kann es nicht lassen wie geliebte Sünden." (An Heckenast, zit. n. Witiko, Winkler-Ausgabe [Anm. 2] Bd. V, Anmerkungen, S. 906). Vgl. a. Sabine Gattermann, "Bewältigung und Verdrängung: Zur Funktion des Schreibens in der Krankengeschichte von Adalbert Stifter," Deutsches Ärzteblatt - Ärtliche Mitteilungen, 77. Jg. (23.1.1980), 2575-79.

76 Vgl. Hein (Anm. 4), passim; für die letzten Ehejahre S. 574ff. 
Wörter vor die erloschenen Inhalte treten. Der Fromme Spruch, nach der Selbstaussage des Dichters eine seiner "edelsten und lebensvollsten" Dichtungen," behandelt Zeit, Raum, Welt, Moralität und Textlichkeit nur noch als ein ausgedehntes Nichts. Bedeutungslos wird die Sprache ein Simulakrum ihrer selbst. Dergestalt bewegt sich der Text, der vom Schweigen handelt, stets mäandernd an der Grenze des eigenen Verstummens.

"So schließen wir die Verhandlung über diesen Gegenstand," sprach die Tante.

"Schließen wir sie," erwiderte der Oheim, "da ja doch nichts zu verhandeln ist."

Sie schlossen, weil wirklich nichts da war, das verhandelt werden konnte. (712)

Die Rede präformiert das Ende der Rede, die Kunst das der Kunst. Der Verschluß des Sprechens, dreifach zelebriert, ist dabei unversehens vom Antidot gegen geistige Irrgänge zu einem poetischen Aphrodisiakum geworden. Stifter arbeitet an einer totalen und absurden Reduktion, in der allein nicht nur die Wahrhaftigkeit der Dichtung, sondern auch ihre Qualität, ja Kunstgenuß überhaupt sich noch behaupten können. Sein altmodisches Sprachspiel des Verstummens birgt die Kunstapokalypsen der Moderne schon in sich, ohne von ihnen zu reden. Er führt die Verpflichtung konstruktiven Denkens bis zu einem Punkt, an dem die Affirmation kahl, leer und endlich lächerlich wird, an dem die reale Welt aufhört, Primärtext für eine sinnvolle ästhetische Deutung zu sein. Durch konsequenten Ausschluß umreißt er ex negativo die Gestalt deformierter Subjektivität, die in der Literatur der Moderne den Sprachträger stellt: das abnorme, das pathologische, das dysfunktionale Ich. Heute, wo diese Ästhetik wortmächtiger Ohnmacht in ihren Möglichkeiten erschöpft scheint, wird das Verstummen des alten Stifter universell.

$\pi$ BS, 749. 